\title{
Interventional Techniques for Bone and Musculoskeletal Soft Tissue Tumors: Current Practices and Future Directions - Part I. Ablation
}

\author{
Danoob Dalili, MB BS, FRCR, EDiMSK ${ }^{1,20}$ Amanda Isaac, MBChB, MRCS, FRCR ${ }^{2 \oplus}$ \\ Alberto Bazzocchi, MD, PhD ${ }^{3}$ Gunnar Åström, MD, $\mathrm{PhD}^{4(}$ Jonas Bergh, MD, $\mathrm{PhD}^{5(1)}$ \\ Radhesh Lalam, MBBS, MRCS, FRCR ${ }^{6}$ Marc-André Weber, MD, $\mathrm{MSc}^{7 \odot}$ \\ Jan Fritz, MD, PD, DABR, RMSK ${ }^{8}$ Ramy Mansour, MBChB, MSc, FRCR ${ }^{10}$
}

${ }^{1}$ Department of Radiology, Nuffield Orthopaedic Centre, Oxford University Hospitals NHS Foundation Trust, Oxford, United Kingdom

Address for correspondence Danoob Dalili, MB BS, FRCR, EDiMSK,

${ }^{2}$ School of Biomedical Engineering and Imaging Sciences, Kings Department of Radiology, Nuffield Orthopaedic Centre, Windmill College London, London, United Kingdom

${ }^{3}$ Diagnostic and Interventional Radiology, IRCCS Istituto Ortopedico Road, Oxford OX3 7LD, United Kingdom (e-mail: Danoob.Dalili@nhs.net).

Rizzoli, Bologna, Italy

${ }^{4}$ Department of Immunology, Genetics and Pathology (Oncology) and department of Surgical Sciences (Radiology), Uppsala

University, Uppsala, Sweden

${ }^{5}$ Department of Oncology, Karolinska Institutet, Karolinska

University Hospital Stockholm, Sweden

${ }^{6}$ Department of Radiology, Robert Jones and Agnes Hunt

Orthopaedic Hospital, Oswestry, United Kingdom

${ }^{7}$ Institute of Diagnostic and Interventional Radiology, Paediatric Radiology and Neuroradiology, University Medical Centre Rostock, Rostock, Germany

${ }^{8}$ Department of Radiology, New York University Grossman School of Medicine, New York

Semin Musculoskelet Radiol 2020;24:692-709.

\begin{abstract}
Musculoskeletal (MSK) image-guided oncologic intervention is an established field within radiology. Numerous studies have described its clinical benefits, safety, cost effectiveness, patient satisfaction, and improved quality of life, thereby establishing image-guided oncologic intervention as a preferred pathway in treating patients presenting with specific benign MSK tumors. But there is a paradigm shift on the horizon because these techniques may also support established pillars (surgery, systemic treatment, radiotherapy) in the treatment of malignant MSK tumors. Unlike benign tumors, where they are used as primary therapy lines with curative intent, such interventions can be selected for malignant tumors as adjuvant treatment in painful or unstable bone or soft tissue lesions or as more palliative therapy strategies. Using examples from our clinical practices, we elaborate on the benefits of applying a multidisciplinary approach (traditionally involving MSK radiologists, oncol-

Keywords

- musculoskeletal intervention

- tumor

- ablation

- sarcoma

- metastasis ogists, orthopaedic surgeons, microbiologists, pathologists, physiotherapists, and pain management experts), ideally within a sarcoma treatment center to deliver a patientspecific therapy plan and illustrate methods to assess the benefits of this model of care. In this article, we review the current repertoire of ablation techniques, demonstrate why such procedures offer value-based alternatives to conventional treatments of specific tumors, and reflect on future directions. Additionally, we review the advantages and limitations of each technique and offer guidance to improve outcomes.
\end{abstract}

Issue Theme Bone and Soft Tissue Tumors: Part 2; Guest Editors, Radhesh Lalam, MBBS, MRCS, FRCR and MarcAndré Weber, MD, MSc
Copyright $\odot 2020$ by Thieme Medical Publishers, Inc., 333 Seventh Avenue, New York, NY 10001, USA. Tel: +1(212) 760-0888. ISSN 1089-7860. 
Musculoskeletal (MSK) intervention remains a fascinating specialist area in MSK radiology. It has evolved as a result of advances in imaging technology leading to earlier detection and more accurate diagnosis of benign and malignant tumors, increased patient demands and expectations, as well as increased incidence of tumors detected within an aging population. In addition, advancements in precision oncology including systemic regimes have resulted in more targeted cancer therapy and hence more extended life expectancy in cancer patients. Together with the ability to harness the creativity and ingenuity of the technical approaches related to image-guided interventions in more recent years, as MSK interventionalists, we are witnessing a renaissance in our profession.

Many percutaneous image-guided interventions successfully reduce the volume of tumors, thereby reducing disease load, improving mechanical stability, and reducing pain caused by focal disease or neural compression syndromes. Because the primary mode of therapy is focused locally, aiming at disrupting cellular integrity of tumor cells, such interventions do not compromise neoadjuvant therapy (chemotherapy and radiotherapy that until the present remain gold standard therapies for some tumors and are effective strategies for controlling metastatic disease), and most procedures are performed in day-case settings. ${ }^{1}$ Image-guided interventions can therefore be seamlessly integrated into patient management plans as an additional tool in our repertoire, without causing any delays or adverse reactions. In other cohorts of patients, image-guided interventions have been validated as the current gold standard, such as radiofrequency ablation (RFA) treatment of osteoid osteoma (OO) and osteoblastoma $(\mathrm{OB})^{2,3}$

Primary bone tumors are relatively rare when compared with secondary (skeletal metastatic) disease. According to most cancer registries, ${ }^{4-6}$ benign primary bone tumors are detected much more commonly than malignant primary bone tumors (sarcoma). Osteo/chondrosarcoma prevalence is estimated to be $<0.2 \%$ of all malignancies diagnosed in the United States. ${ }^{6}$ Incidence rates for bone sarcoma are projected to fall by $5 \%$ in the United Kingdom between 2014 and 2035, to 1 case per 100,000 people by 2035 , but incidence rates have remained stable for most of the main soft tissue sarcoma subtypes in the country since the mid-1990s. Rates of liposarcoma, fibroblastic sarcoma, rare soft tissue sarcoma variants, and sarcoma not otherwise specified increased between 1996 and 1998 and between 2008 and 2010 while rates of leiomyosarcoma decreased. Changes in the definition of some subtypes may partly explain the trends. Overall, the incident of MSK sarcoma remains low across Europe. ${ }^{7-9}$

However, most benign bone tumors are in fact asymptomatic and are therefore undetected in the general population, ${ }^{5}$ rendering it challenging to extract precise epidemiological statistics regarding their prevalence. Bone metastases, in contrast, are common, can present with variable symptoms, and are often associated with a poorer prognosis when compared with patients who have the same histologic grade and cancer type but no skeletal metastasis. ${ }^{9}$ Tumors are detected as incidental findings, during routine
Table 1 World Health Organization 2017 classification of soft tissue tumor groups ${ }^{\mathrm{a}}$

\begin{tabular}{|l|l|}
\hline 1 & Adipocytic tumors \\
\hline 2 & Fibroblastic/myofibroblastic tumors \\
\hline 3 & So-called fibrohistiocytic tumors \\
\hline 4 & Smooth muscle tumors \\
\hline 5 & Pericytic (perivascular) tumors \\
\hline 6 & Skeletal muscle tumors \\
\hline 7 & Vascular tumors \\
\hline 8 & Gastrointestinal stromal tumors \\
\hline 9 & Nerve sheath tumors \\
\hline 10 & Chondro-osseous tumors \\
\hline 11 & Tumors of uncertain differentiation \\
\hline 12 & Undifferentiated/Unclassified sarcomas \\
\hline
\end{tabular}

${ }^{a}$ Adapted from Vilanova et al. ${ }^{10}$

staging or when present with skeletal-related events including pain, fractures, or neural compromise requiring further interventions such as radiotherapy, surgery, or, more frequently, image-guided percutaneous interventions ${ }^{9}$ to treat the tumor or its locoregional sequelae.

The World Health Organization introduced a new classification for soft tissue tumors in 2013 that was last updated in May 2020 (-Table 1). ${ }^{10,11}$ All of these may arise in the MSK system and are considered primary tumors if arising within one of the main structures (e.g., muscle, fat, fibrous layers and fascia, vessels, or nerves) or secondary if they are metastatic or arise as sarcomas in cancer survivors. ${ }^{12,13}$

Although benign tumors have lower morbidity and much lower mortality compared with malignant tumors, consistently applying similar fundamental oncologic principles when managing secondary pathologic fractures remains critical to improving clinical outcomes. ${ }^{1}$ Failure to identify and consider biological behaviors of such tumors can result in inappropriate surgical or interventional strategies, use of unsuitable surgical implants, and increased morbidity/mortality rates, both in childhood as well as later in life.,14

In this article, we share our experience in bone and MSK soft tissue ablation interventions including benign tumors, sarcoma and metastases, and myeloma from several internationally renowned centers, aiming to provide a comprehensive overview of methods to tackle common tumors (primary and secondary), axial and nonaxial, that may be encountered in an MSK practice. We examine the utility of the versatile image-guided interventional repertoire, which as such allows for patient-tailored management plans that may involve single or combined procedures, guided by one or more imaging modality. We review a variety of technically challenging procedures performed in specialist centers and elaborate on emerging methods of treatment for curative intent, pain palliation, and local tumor control. Throughout this article, we adhere to current standardized terminology and reporting criteria. ${ }^{15}$ 


\section{Imaging Requirements}

\section{Preintervention}

Baseline imaging includes conventional radiographs ( $\mathbf{- F i g . ~ 1 a ) ~ t o ~}$ characterize the tumor and assist in decision making in multidisciplinary meetings. ${ }^{16}$ In addition, plain radiographs are a useful and quick tool to assess for pathologic fractures. Magnetic resonance imaging (MRI) is performed in all patients for further characterization of the tumor, specifically its morphology, matrix, and wall, thereby differentiating between aggressive and nonaggressive lesions. It allows assessment of its relation to the adjacent neurovascular structures ( - Fig. 1 b) and facilitates identifying those who might benefit from image-guided interventions. ${ }^{17}$ Computed tomography $(\mathrm{CT})$ is often performed to characterize the calcific matrix (such as in chondral tumors and hemangiomata) and assess the extent of cortical breach delineating pathologic fractures. ${ }^{18}$ Ultrasound (US) imaging is reserved for soft tissue and superficial tumors, both for initial assessment and for targeted interventions such as US-guided biopsies (- Fig. 1c) and RFA of superficial nerves.
Patients presenting with a "solitary tumor" with no known malignancy or MSK tumors elsewhere should never be managed with the assumption that this bone tumor is a metastatic carcinoma. Instead, a comprehensive diagnostic work-up should be followed including histologic diagnosis and grading, age, clinical findings, history, and genetic expression before definitive surgical, oncologic, or imageguided interventions. ${ }^{14,16}$

Novel and established functional imaging techniques such as single-photon emission computed tomography/CT, positron emission tomography/CT (-Fig. 2), MR perfusion (perfusion-weighted imaging [PWI]), MR diffusion (diffusion-weighted imaging), and dynamic contrast enhancement (DCE) analysis allow accurate visualization of the active and most cellular components of the tumors that can then be targeted with image-guided interventions, ${ }^{19-21}$ as well as permitting assessment of response to such interventions on subsequent follow-up ${ }^{22}$ (-Fig. 2). When planning interventions or follow-up in tumors located adjacent to metallic

a
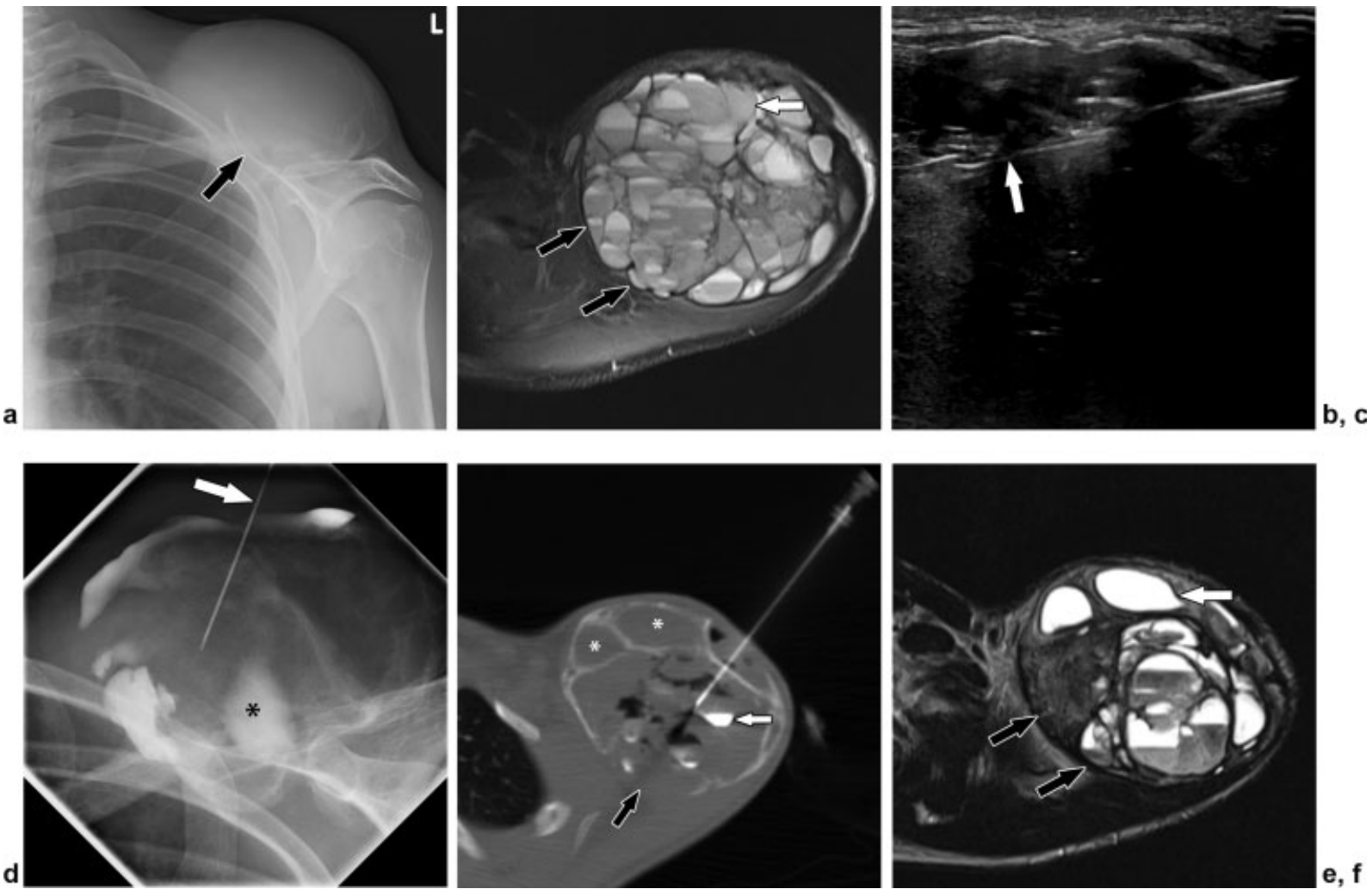

Fig. 1 Sclerotherapy work-up for an aneurysmal bone cyst $(A B C)$ of the left distal clavicle in a 17-year-old boy. (a) Anteroposterior radiograph shows a large expansile bone lesion centered on the distal clavicle (black arrow). (b) Axial T2-weighted fat-saturated magnetic resonance imaging (MRI) demonstrates the extent of the lesion, presence of multiple fluid-fluid levels (more sediment than fluid; white arrow) within very thin, delicate walled cysts permitting small caliber needle puncture. This is apparent particularly at the posteromedial margin (black arrows). (c) Ultrasound-guided 14G coaxial core needle (white arrow) biopsy confirmed histology of a benign ABC. (d) A 22G needle (white arrow) aspirates and decompresses the blood-filled cystic spaces while puncturing the thin-walled cystic loculations to allow communication between them. lodinated contrast (black asterisk) is injected before sclerosant infiltration to ensure the absence of communication with large draining veins, minimizing the risk of air or thrombotic embolus. (e) The last of three treatment cycles is performed under computed tomography guidance to precisely target the needle tip into the residual loculated aspects of the lesion (white arrow) while assessing treatment response. Note reduction in total tumor volume, progressive cortical thickening (black arrow), and centripetal osseous sclerosis (asterisks). (f) Follow-up MRI 4 months after initial intervention demonstrates further involution of the lesion and reduction of the active endothelial surface area, with only a few residual fluid-fluid levels (higher fluid-to-sediment ratio; white arrow) consistent with excellent treatment response. Given its size and location, the tumor was subsequently surgically resected. Sclerotherapy permitted en bloc enucleation of a well-circumscribed tumor reinforced with a thick sclerotic osseous shell (black arrows). Presurgical sclerotherapy benefits include reduction in procedural blood loss, shorter operative time, and minimizing the risk of cyst spillage and seeding. 

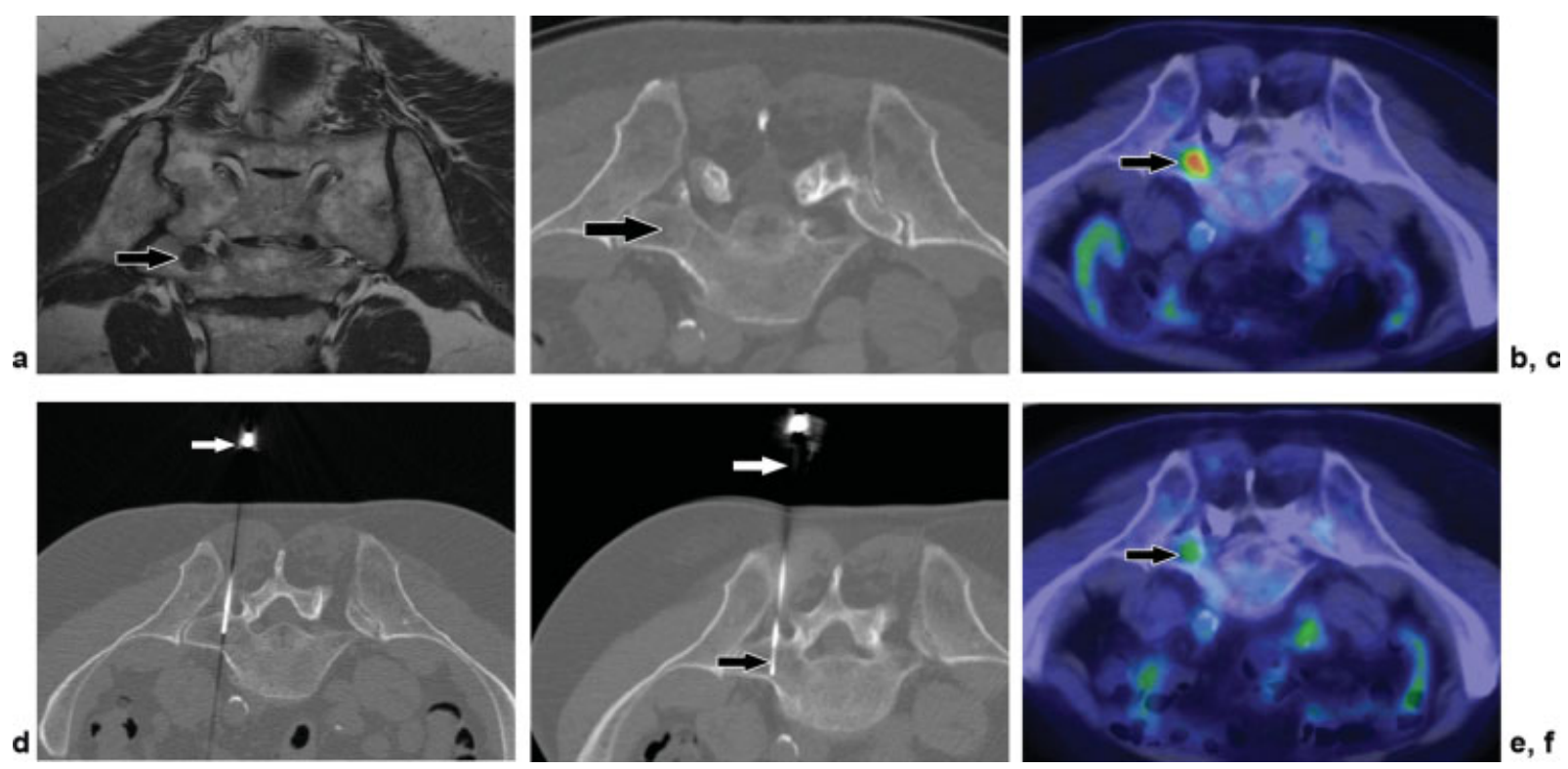

Fig. 2 Computed tomography (CT)-guided radiofrequency ablation (RFA) of a CT occult gastrointestinal stromal tumor bone metastasis in an 82-year-old man thought to be in clinical remission. (a) Coronal oblique T1-weighted magnetic resonance imaging (MRI) performed as part of a routine lumbar spine MRI in a patient with sacral pain demonstrates a hypointense T1 lesion in the left sacral ala (arrow). (b) On the axial CT component of the follow-up positron emission tomography (PET)/CT scan, the metastasis is relatively occult with faint mixed lucent/sclerotic characteristics (arrow). (c) The fused PET images demonstrate a focus of increased fluorodeoxyglucose (FDG) activity relating to the tumor (arrow). (d) CT-guided core bone biopsy (white arrow) of the lesion confirms bone metastasis from the primary gastrointestinal stromal tumor. (e) Following multidisciplinary tumor board discussion, the tumor was treated with RFA. Six ablation cycles encompassing the entire tumor volume are performed (each 90 degrees for 3 minutes) with the electrode (black arrow) inserted into the epicenter of the tumor using a coaxial approach (white arrow) under CT guidance. (f) Follow-up PET/CT 1 month postablation demonstrates response with reduction in the degree of FDG uptake, correlating with the patient's significant reduction in pain.

implants, we advocate implementing metal artifact reduction protocols for both CT and MRI. ${ }^{23-25}$

\section{Image-guided Biopsy}

The so-called do-not-touch lesions do not receive preprocedural biopsy. However, if interventional procedures are required, for aesthetic or mechanical reasons or for symptom control, and with the exception of typical OOs and myositis ossificans, most tumors would receive an intraprocedural biopsy, and any specimens obtained during the procedure would be sent for histologic evaluation to obtain a definitive diagnosis. This is necessary to achieve best practices and optimize patient care. Biopsies are performed before planning therapeutic procedures in all "indeterminate," "suspicious," "probably malignant," and/ or "definitely malignant" tumors for histologic diagnosis and grading. The results should be discussed in multidisciplinary tumor board meetings consisting of at least a tumor surgeon, a pathologist, and an experienced MSK radiologist ${ }^{16,26}$ before any interventions. Power drills may be used under image guidance to traverse thick cortices and dense sclerotic lesions. The ability to visualize the use of instruments, including their tips, to confirm location within a tumor and depict any instrumentrelated complications is another important safety measure. Modern imaging protocols allow better visualization of instruments, both on CT and MRI. ${ }^{23,24,27}$

\section{Postintervention}

All interventions are implemented under image guidance. ${ }^{28} \mathrm{~A}$ postprocedural imaging check is performed to ensure satisfaction with the procedural steps and assess for any potential immediate postprocedural complications. Patients with neural compromise often receive an MRI within 6 weeks to evaluate the spinal cord and nerves. In our practice, MRI is performed in all patients to assess the response to the intervention and/or plan further treatments. Although there is no standardized follow-up regime exemplified in previous studies, ${ }^{22}$ we recommend that all patients undergoing complex interventional procedures have a short-term ( $\sim 2-3$ months) and long-term ( 9-12 months after RFA) follow-up examinations.

In our collective experience this may not be required in routine procedures or benign lesions such as OOs unless the patient reports persistent or new-onset symptoms. Postintervention imaging includes assessment of the volume of the tumor, ${ }^{15,29,30}$ cortical thickening, periostitis and/or a periosteal reaction, bone or soft tissue deformity, tumoral signal changes, adjacent bone marrow and/or soft tissue edema, cortical or medullary sclerosis, ${ }^{31}$ joint effusion, synovitis, contrast enhancement patterns, or presence of locoregional lymph nodes. Imaging protocols should ideally match the preprocedural studies to minimize any bias that could be introduced by technical factors. Ideally, these postinterventional studies should be assessed by a radiologist experienced in the subtleties of undertaking these interventions.

\section{Antibiotics}

Antibiotic prophylactic cover is advised unless contraindicated, ${ }^{32}$ and routinely $1.5 \mathrm{~g}$ cefuroxime is administered intravenously in adults (or adjusted doses per kilogram in children). If patients have underlying conditions causing 
immunosuppression (e.g., rare hereditary disorders, sicklecell disease, or individuals with a previous splenectomy), antibiotic cover is adjusted accordingly. We advocate liaising closely with the local microbiology team to comply with upto-date guidance.

\section{Pain Management and Postprocedural Care}

Most procedures are performed under general anesthetic, sedation, or on-demand nitrous oxide $\left(\right.$ Entonox $^{\circledR}$ ). There is some controversy and vast variation in practices surrounding sedation by nonanesthetists. ${ }^{33}$ Regional analgesia can provide pain relief but also improves circulation to the region, and it helps prevent reflex sympathetic dystrophy. ${ }^{34}$ Pre- and postprocedural visual analog pain scores are documented to assess response to the intervention and early detection of the need for further management. Lignocaine is introduced subcutaneously and into the needle tract, followed by infiltration of 2 to $5 \mathrm{~mL}$ bupivacaine or ropivacaine into the periosteum or around a soft tissue tumor capsule, without breaching its cortex/shell to minimize the risk of seeding (in neoplastic tumors). Intraprocedural and postprocedural anesthetic cover is offered intravenously by the anesthetist supervising the general anesthetic. In certain scenarios where MR interventional procedures are contemplated, adjuvant MR-guided nerve blocks can be performed to aid with pain management during and after the interventions. ${ }^{35}$ Patients are usually discharged home within 24 hours with oral analgesics (taken when required within their daily allowance), following a physical examination to depict any postprocedural complications precluding safe discharge. Depending on the location of the tumor, on discharge from hospital, the patient is generally advised to return to daily activities, mobilize as pain allows, and avoid excessive activity in the first few weeks, particularly with bone tumors. This allows time for bone healing and consolidation of the tumors by new bone filling the tumor cavity, minimizing the risk of fractures.

\section{Ablation Procedures}

Ablative modalities are classified into chemical ablation (i.e., nonenergy ablation) or energy-based ablation (i.e., thermal and nonthermal). ${ }^{15}$

\section{Chemical Ablation}

The mode of therapy is to deliver the minimum volume and minimum concentration of a sclerosing agent into the cavity of a predominantly cystic tumor or lumen of a venous malformation, to delineate its walls from within for maximum cytotoxic effects. $^{36}$

\section{Technique}

To confirm intracystic positioning of the needle tip in aneurysmal bone cysts (ABCs), aspiration is performed, with the aim of yielding free-flowing blood from the cavity that also helps reduce intracavitary pressure. Soluble iodinated contrast (an average of diluted 1:2 of $3 \mathrm{~mL}$ iohexol) is then injected under direct fluoroscopic control (-Fig. 1d and -Fig. 3b), intermittent CT or MRI (-Fig. 4), producing a cystogram, demonstrating the extent of the lesion and perhaps more importantly, ensuring no intravascular communication with draining veins or intradural leak (spinal tumors) and to confirm integrity of the cortex. ${ }^{37}$ In the context of ABCs, if considerable draining veins are visualized, the needle tip is repositioned before injecting the sclerosant, followed by repeat contrast cystography, to reduce the likelihood of leakage or thrombosis-related complications. ${ }^{38}$ The sclerosing agent is then applied, to cover as much of the tumor from within as possible, followed by full aspiration to minimize the risk of leakage. ${ }^{37}$ The body then heals by consolidation of the cavity in case of bony tumors (such as ABCs and giant cell tumors [GCTs]) or involution (arteriovenous malformation or neuromata). Such procedures can be performed under fluoroscopy, CT, or MR guidance. ${ }^{39}$

\section{Applications}

- Benign: Sclerotherapy of ABCs (-Fig. 1d, e and - Fig. 3b), AVMs (-Fig. 4), hemangiomas, and GCTs. Sclerosing agents include ethanol, denosumab, doxycycline, polidocanol, sodium tetradecyl sulfate (STS), and hydrogen peroxide, ${ }^{40}$ as well as warm Ringer's lactate solution, ${ }^{40}$ phenol, or liquid nitrogen. STS and doxycycline can be delivered as foam, for improved coverage and dissemination within the tumor cavity, with reduced side effects from foam leakage when compared with fluids, and they are therefore preferred over other sclerosants. ${ }^{38}$

- Aggressive tumors: As adjuvant therapy to treat locally advanced giant cell bone tumors. ${ }^{40}$ Surgery en bloc remains the treatment of choice for secondary ABCs and malignant cystic tumors (primary and metastatic).

Advantages: Warm Ringer's lactate heated to $50^{\circ} \mathrm{C}$ combined with thermoablation techniques was shown to achieve maximal GCT cellular toxicity with minimal chondrocyte and osseous toxicity, in addition to minimal endothelial vascular damage. ${ }^{40}$

Complications: Complication rates are low and include iatrogenic fractures, thrombosis, embolism, infection, hemorrhage, neurovascular damage, and skin necrosis. ${ }^{36}$

\section{Thermoablation}

\section{Mode of Therapy}

The aim is to induce focal and rapid change in the temperature of cells within a tumor, destroying their membranes and inducing necrosis, coagulation, or both while preserving adjacent vital structures and causing minimal adjacent cellular damage. Histologically, normal cells have the ability to produce heat shock proteins that can protect them from heat-induced apoptosis but is not expressed in tumor cells. ${ }^{40}$ This can be achieved by introducing core temperature changes to tumors of up to 45 to $95^{\circ} \mathrm{C}$ with thermoablation of -45 to $-160^{\circ} \mathrm{C}$ with cryoablation (CA). Subsequent to ablation, the body heals with involution of the ablation zone over weeks to months in case of soft tissue tumors, ${ }^{15}$ and with partial or complete bone filling and sclerosis in bone tumors (-Figs. 5 and $\mathbf{6}$ ) unless combined with cementoplasty in the same setting. 

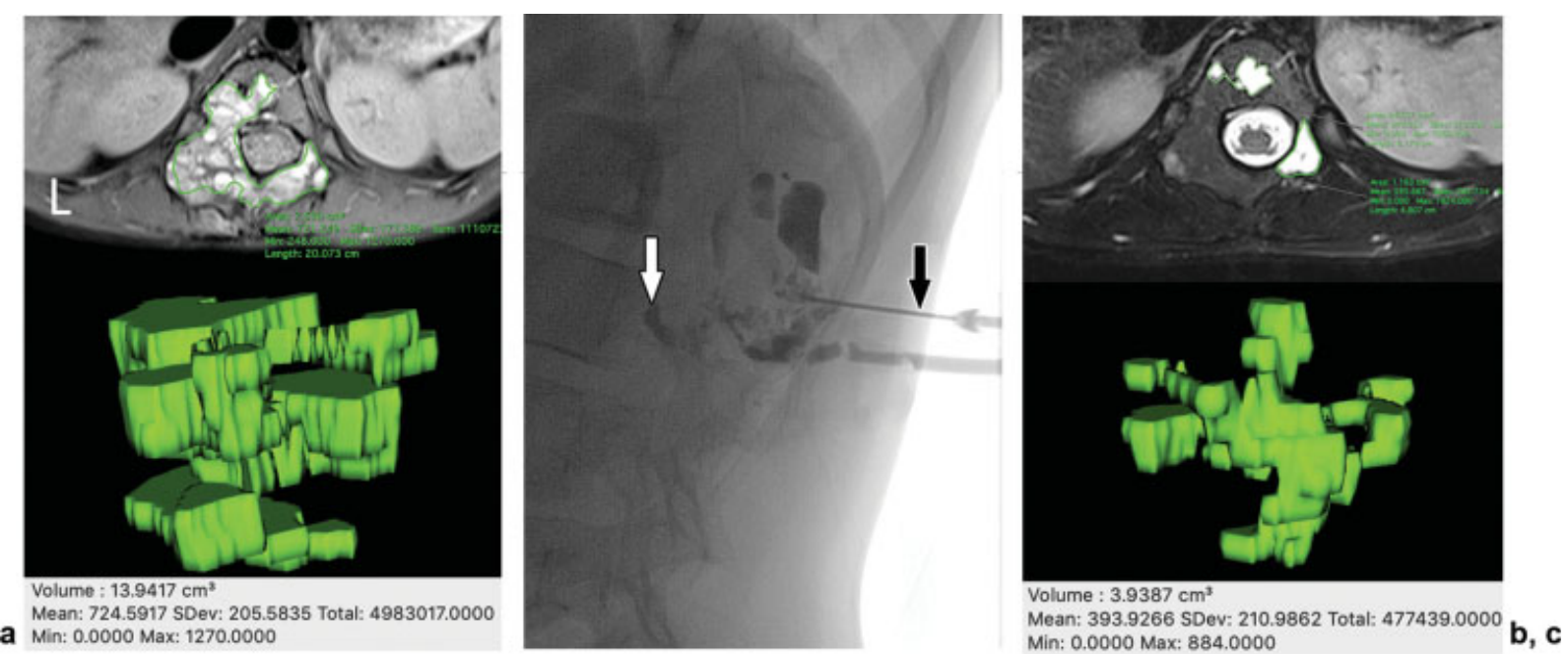

Fig. 3 Pre- and postsclerotherapy treatment assessment for an extensive spinal aneurysmal bone cyst (ABC) in a 9-year-old girl. (a) Baseline axial T2-weighted proton-density images demonstrate an extensive spinal $A B C$ resulting in crowding of the central cauda equina nerve roots with resultant pain and leg weakness/numbness. Magnetic resonance imaging (MRI)-based lesion segmentation volume (green) illustrates the burden of disease $\left(13.9 \mathrm{~cm}^{3}\right.$ ) pretreatment. (b) Following multidisciplinary tumor board discussion, fluoroscopic-guided sclerotherapy using sodium tetradecyl sulfate foam was opted as a primary treatment strategy. Before drug administration, iodinated contrast is injected with a $22 \mathrm{G}$ needle (black arrow) to ensure no intradural or intravascular leak. Contrast is seen extending into a deep pedicular portion of the tumor (white arrow). (c) Follow-up MRI at 24 months posttreatment demonstrates $>70 \%$ reduction in tumor volume with remodeling of the previously expanded bone and a capacious central spinal canal. Additionally, the visual analog pain score was reduced from 8 to 1 (11-point scale).
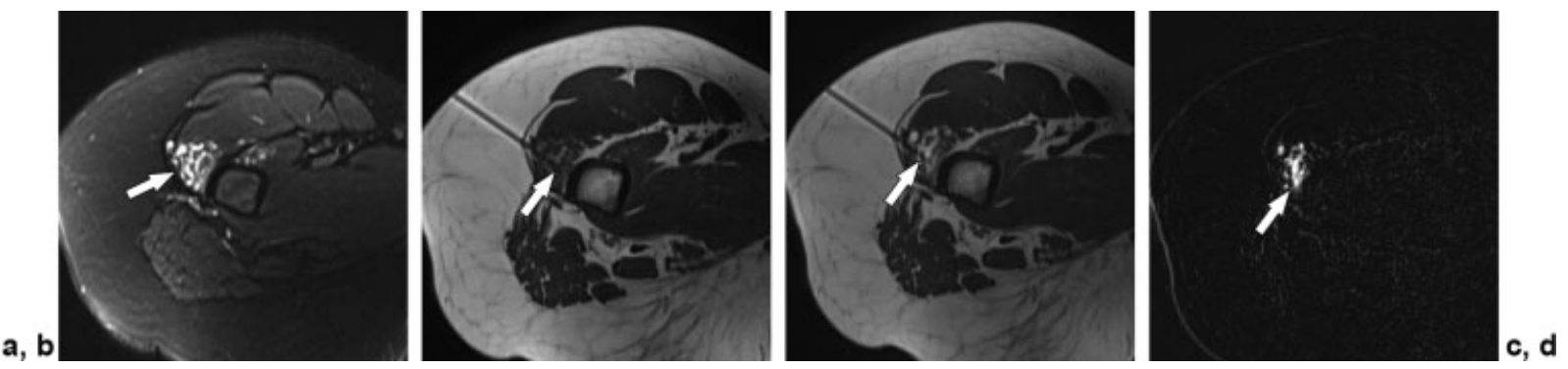

Fig. 4 Magnetic resonance imaging (MRI)-guided sclerotherapy of a venous malformation-type vascular anomaly of the left thigh in a 34-year-old woman. (a) Procedural axial T2-weighted turbo spin-echo MR image with fat suppression demonstrates a multilobular vascular lesion (arrow) predominantly located within the left vastus lateralis muscle. (b) Procedural axial T1-weighted turbo spin-echo MR image demonstrates the tip of an MRI conditional 22G needle (arrow) inside the lesion. (c) Procedural axial T1-weighted turbo spin-echo MR image demonstrates filling the serpentine vascular spaces with gadolinium contrast-enhanced sclerosant (arrow). (d) Procedural axial subtraction MR image demonstrates filling of the vascular spaces of the venous anomaly with gadolinium contrast-enhanced sclerosant (arrow) to better advantage, consistent with technical success.

\section{Advantages}

When compared with surgery, thermoablation could save $>€ 5,000$ per procedure while offering at least similar if not superior success rates. ${ }^{3}$ Advantages also include suitability for real-time imaging guidance and the ability to perform ablative procedures on outpatient/day-case settings. ${ }^{41}$ In addition, percutaneous ablation, when compared with other nonpercutaneous (noninvasive) ablation treatments such as radiotherapy and magnetic resonance-guided high-intensity focused ultrasound (MRg-HIFU), offers the benefits of combining bone consolidation with ablation within the same intervention, thus significantly reducing the risk of secondary fracture. ${ }^{41}$ Secondary gains include reduction in pain levels via local destruction of pain-sensitive nerves as well as reducing the production of cytokines and growth factors produced following tumor necrosis, disruption of internal cellular membranes, and/or coagulation of its cellular proteins. ${ }^{42}$ Thermoablation thus improves the quality of life (QOL) of patients with malignancy or rapidly growing benign expansile tumors that trigger pain directly by mechanical compression, through associated neoangiogenesis and its accompanying abnormal vasa nervosa, or directly within an 00 nidus. Oncology patients often have multiple comorbidities and a limited life expectancy. Thus they benefit most from procedures that can simultaneously target their tumors, reduce locoregional and therefore overall disease load, as well as treat its secondary pain symptoms while reducing the time spent in hospital settings. In addition, thermoablation serves as a last resort for patients in whom conventional therapies (surgery, ${ }^{43}$ radiotherapy, and/or chemotherapy) have been exhausted.

\section{Applications}

1. Primary applications of thermoablation: Each will be subsequently discussed according to the technique used (e.g., CA, RFA, etc.).

2. Thermoablation combined with stabilization techniques is used successfully for treating spinal tumors causing 
a, $\mathbf{b}$
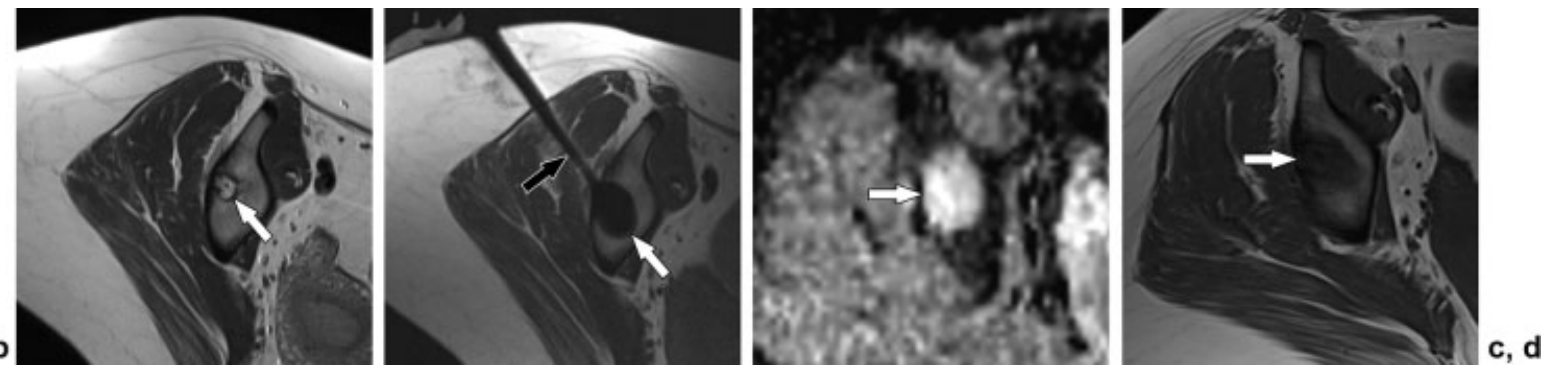

Fig. 5 Cryoablation guided by magnetic resonance imaging (MRI) of a right supra-acetabular osteoid osteoma (OO) in a 20-year-old woman. (a) Axial intermediate-weighted MR image demonstrates an ovoid right iliac bone lesion with a sclerotic margin (arrow). (b) Following the creation of a bony tunnel for access to the $\mathrm{OO}$ with a coaxial MRI conditional bone trocar drill system, the cryoprobe (black arrow) was introduced with the freezing filament locating centrally in the nidus. MRI facilities exquisite visualization of the ice-ball growth (white arrow) during several freeze-thaw cycles, demonstrating ice-ball coverage of the entire lesion with the ice-ball margins extending beyond the margins of the $\mathrm{OO}$ while maintaining a safe distance to the adjacent vital structures. Follow-up MRI at 12 months with diffusion-weighted imaging and apparent diffusion coefficient (ADC) map (c), as well as T1-weighted MR images (d), demonstrate high signal intensity of the ablation zone (arrow) on the ADC map without evidence of diffusion restriction to suggest remaining neoplastic cells. Axial T1-weighted MR image demonstrates hypointensity of the ablation zone (arrow), consistent with homogeneous sclerosis and successful ablation of the OO.
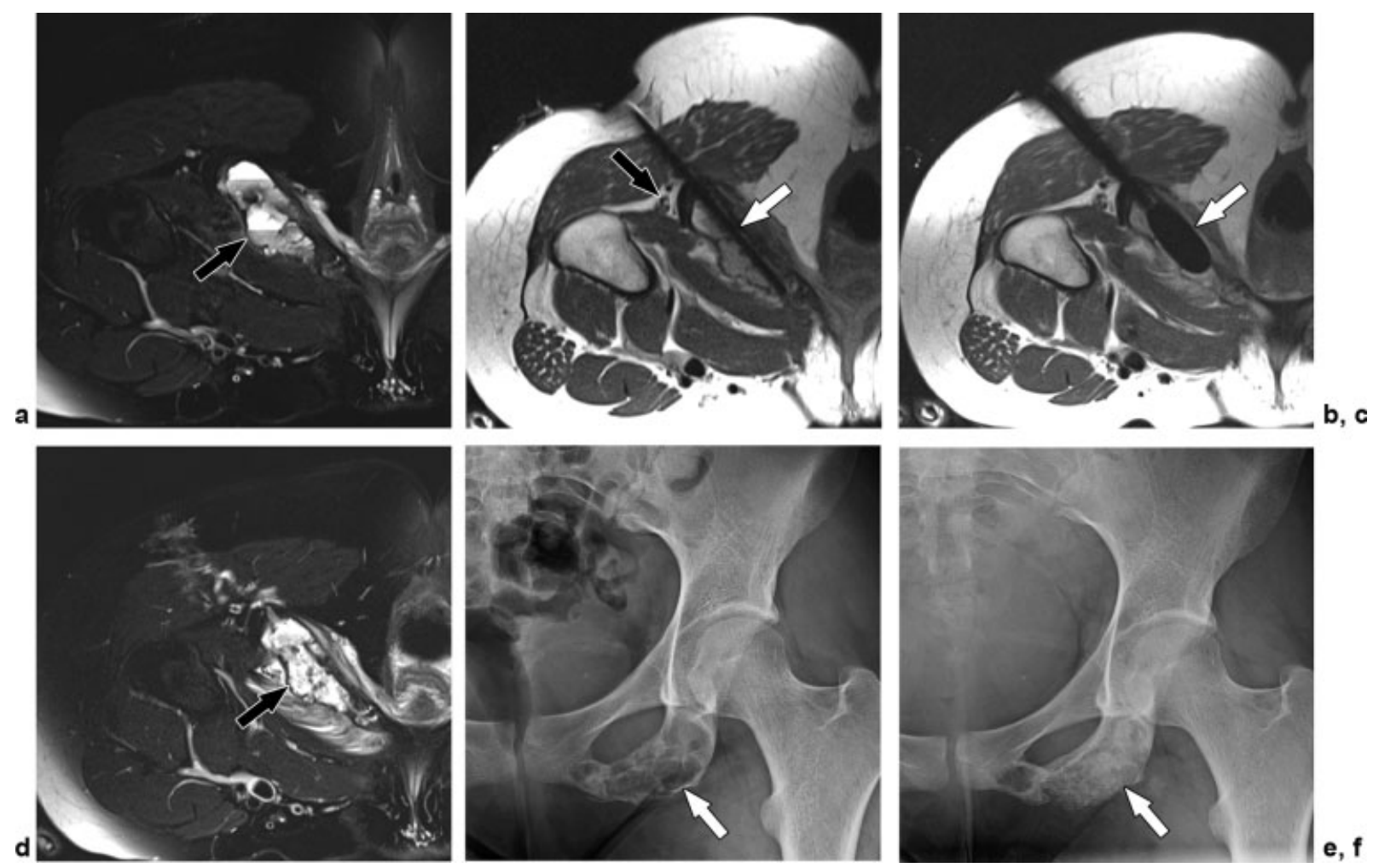

Fig. 6 Cryoablation guided by magnetic resonance imaging (MRI) of an aneurysmal bone cyst (ABC) in an 18-year-old woman. The procedure and MR guidance were performed with the patient in a prone position. (a) Procedural prone MRI using an axial T2-weighted turbo spin-echo pulse sequence with fat suppression at the level of the left inferior pubic ramus demonstrates the expansile, multiloculated ABC (arrow) with fluid-fluid levels. (b) Osseous access with a 13G MRI-compatible bone trocar drill system (arrow) using a posterior trans-ischial approach, thereby guaranteeing a safe distance to the sciatic nerve (black arrow). MR affords exquisite soft tissue anatomical detail including visualization of neighboring neurovascular structures for safe needle paths and placement. (c) MRI monitoring of the ice ball (arrow) using an axial accelerated intermediate-weighted turbo spin-echo pulse sequence during multiple freeze-thaw cycles at different locations within the lesion (one shown here) from posterior to anterior to ensure ablation of the entire lesion along its longest diameter. (d) Procedural prone MRI using an axial T2-weighted turbo spin-echo pulse sequence with fat suppression immediately after the cryoablation demonstrates the ablation zone (arrow) and edema in the neighboring obturator externus and adductor magnus muscles. There was no evidence of neurologic impairment following the procedure. Follow-up anteroposterior radiographs at (e) 6 months and (f) 12 months demonstrate healing of the ABC through progressive osseous consolidation and sclerosis (arrows) of the lesion consistent with successful treatment. Pain score was significantly reduced from 7 (pretreatment) to 1 at 12-month follow-up (on a 10-point scale).

secondary kyphosis, cord or nerve root compromise, or myelomalacia. ${ }^{44}$ When conjoining with stabilization, the intervention should be performed as a combined procedure in hybrid theater settings or at least in the same center as surgery, with a short interval between both procedures to minimize if not abolish the risk of complications caused by ablation-induced instability. Patients may require one session or multiple, delivered as a course of treatment. ${ }^{15}$

3. Thermoablation techniques can also be combined with arthroscopy to visualize the articular surface and monitor 
any vascular, neural, or cartilage changes when targeting tumors that are anatomically situated in an intra-articular location, ${ }^{45}$ jettisoning the need for open surgery and curettage. Studies confirm statistically significant higher patient satisfaction rates and QOL scores following thermoablation when compared with matching cohorts treated with surgical resection. ${ }^{46}$

Absolute contraindications to spinal ablations include spinal instability (unless combined with stabilization); local or systemic infection (to avoid dissemination as well as reduced efficacy of ablation), and the presence of life-threatening irreversible coagulopathies. Relative contraindications include metastatic epidural involvement; life expectancy $<3$ months, poor performance status, and widespread visceral metastatic disease. ${ }^{47}$ Careful risk assessment is therefore warranted to enable the radiologists to offer the safest and most effective ablation modality.

\section{Complications}

Rates are low and include transient pain that is observed more frequently in RFA compared with $C A,{ }^{48}$ pathologic fracture, ${ }^{49}$ infection, incomplete ablation of the tumor, damage to adjacent vital structures including postablation neuropraxia that is transient, or axonal edema, fragmentation, and Wallerian degeneration arthropathy that are partially or completely irreversible, ${ }^{50}$ hematoma formation or bleeding, skin burns, ${ }^{51-53}$ or frostbites. There are reported concerns regarding hemorrhage due to absence of a "coagulative phase" in CA, as well as the development of "cryoshock" caused by a florid inflammatory response that may be life threatening, albeit this has been mainly reported with hepatic CA rather than MSK procedures and needs to be researched further. ${ }^{54,55}$ Peritumoral inflammatory response in muscles "cryomyositis" ${ }^{56}$ has also been described in up to $87 \%$ of cases that is detected on follow-up MR imaging of the adjacent muscle tissues for months and on serological testing with transient myoglobinuria, although fortuitously the vast majority of patients are clinically asymptomatic. ${ }^{56}$ Osteonecrosis of adjacent bone has also been periodically reported. ${ }^{57,58} \mathrm{~A}$ recent 10 -year dual-center study proposed the presence of factors increasing the likelihood of complications including tumor size $>3 \mathrm{~cm},{ }^{48}$ previous radiotherapy to the region where the tumor is present, the use of more than three cryoprobes in one setting, as well as combined neoadjuvant radiotherapy/chemotherapy and ablation procedures and/or the presence of multiple comorbidities, frailty, and old age. ${ }^{48}$ Some of these factors have been hypothesized to be due to their negative effects on tissue healing, the ability of bone consolidation postprocedure, and/or association with more histologically aggressive tumors.

\section{Benefits of MR-guided Thermoablation Procedures}

Interventional MRI (iMRI) is a precipitously developing field, rapidly gaining popularity with MSK interventional radiologists. It offers superior contrast and anatomical resolution when compared with other imaging modalities, ${ }^{28}$ allows real-time visualization of the needle tip, and more precise procedure planning. iMRI also allows real-time monitoring of the effects of interventions on surrounding tissues that is particularly relevant in cryotherapy as well as nonpercutaneous ${ }^{57}$ interventions, where tactile feedback during procedures is no longer possible. Advances in scanners and probe designs augment safer, value, and time-efficient practices. ${ }^{59}$

\section{Thermoprotection Techniques}

A minimum distance of $1 \mathrm{~cm}$ has been proposed between the tumor and any vital structure to avoid thermal injuries. ${ }^{57}$ Where anatomically the tumors lie within this safety zone in relation to vital structures, thermoprotection can be achieved by adopting one or more of these strategies:

- Thermal monitoring should be applied throughout the procedure, particularly in the spine, and is often coupled with other thermoprotection techniques. ${ }^{60}$ Nerve temperatures should be rigorously monitored to remain within the physiologic range (i.e., $10-42^{\circ} \mathrm{C}$ ), avoiding neurotoxic thresholds during ablation ${ }^{61}$ in addition to using electromyographic equipment wherever technically feasible. ${ }^{49,50,60}$ Temperature profiles are monitored to assess needle heating when performing MR-guided procedures, to prevent locoregional damage that can be modulated by selection of needle length, needle orientation, and pulse sequence parameters. Local phantom studies are recommended to calibrate each scanner and procedure to amplify safety. ${ }^{62}$

- Hydrodissection/Hydrodisplacement: In this technique, targeted injection and in some cases continuous infusion of isotonic (5\% dextrose in water, sterile water Ringer's solution) or ionic (normal saline) solution creates mass effect, with a physical barrier interposed between the tumor and surrounding vulnerable structures, displacing them away from the ablation zone. ${ }^{57}$ In addition, the technique inherently minimizes the heat-sink effects of nearby vessels, by displacing them away, ${ }^{57}$ thereby improving the efficacy of thermoablation on the tumor. The volume of injectant may vary from a few milliliters (in the epidural space) to several liters (intra-abdominal), and a combination with iodinated contrast: solution in a ratio of 1:50 was reported as optimal for facilitating visibility during CT-guided procedures and may even illustrate concealed structures while minimizing streak artifact. ${ }^{63}$ Saline offers excellent contrast resolution properties on iMRI-guided procedures and can be safely used during CA, interstitial laser ablation (ILA), and microwave ablation (MWA) due to their nonelectric mechanisms, but it should be avoided with RFA because its ionic nature propagates electrical current into nearby tissues. ${ }^{63}$ Therefore, 5\% dextrose in water is favored in RFA due to is nonionic and iso-osmolar nature creating both an electrical and physical barrier around the ablation zone. Chiba needles (20-22G, 100-150 mm, Chiba Needle MRI; Somatex, Teltow, Germany) are routinely applied to induce artificial ascites for abdominal wall tumors, procedures near the diaphragm, or in the spine to displace and protect neural structures $^{47}$ (- Fig. 7).

- Artificial joint effusion when performing intra-articular procedures, to increase the distance between the ablation zone and the cartilage layer. ${ }^{45}$ 
- Pneumodissection/Gas dissection: Injection of air or carbon dioxide $\left(\mathrm{CO}_{2}\right)$ into the perineural or epidural space, for spinal, chest, or abdominal wall procedures as well as for treating retroperitoneal tumors. ${ }^{57,64} \mathrm{CO}_{2}$ carries a lower risk of potential gas embolism that could be life threatening, ${ }^{3,57}$ is absorbed slower, and it has more superior thermal insulation properties when compared with air. This technique can be used with all modalities except US, due to poor sound conduction rendering the dissection plane a poor acoustic window. ${ }^{57}$ The total injected volume varies from 3 to $5 \mathrm{~mL}$ (for epidural or perineural procedures to $1,500 \mathrm{~mL}$ for abdominal procedures). In contrast to fluids used in hydrodissection that tend to follow gravitational forces, gas tends to rise in a nondependent distribution. This may therefore influence patient positioning for procedures and the choice of thermoprotection used ${ }^{47}$ ( - Fig. 7 ).

- Manual manipulation: To displace bowel loops during abdominal procedures, it is successful in moving bowel with up to $2.6 \mathrm{~cm}$ separation between tumor and bowel. Although this is feasible during MRI and US-guided procedures, due to radiation risks it has limited use with CT and fluoroscopy-guided procedures. ${ }^{57}$

- Skin warming: To avoid contact between CA probes and to minimize risk of skin frostbite, we interpose gloves filled with warm saline in between the probes to separate them and for additional dermal protection (-Fig. 8).

- Insertion and insufflation of angioplasty or endoscopic balloons ${ }^{49,50}$ is commonly used to displace bowel loops during renal ablations effectively even when other thermoprotection techniques fail. ${ }^{57}$ However, the technique requires placement of several balloons and maintaining their initial position, which is time consuming, costly (as it requires the use of additional devices), and carries some complication and radiation risks.

- In vivo protection: With CA, breast and lung tissues are relative thermal insulators that may limit ice-ball propagation when performing soft tissue CAs. Connective tissue and fibroblasts are highly resistant to freezing, acting as protective barriers when performing CA next to vital structures, enabling tissue repair rather than destructive scarring. 65

\section{Thermoablation Techniques}

\section{Percutaneous Thermal Ablation Procedures}

\section{Radiofrequency Ablation Technique}

Procedures are performed under general anesthetic due to increased pulse rate during the radiofrequency (RF) phase and possible sympathetic response, particularly when RF is applied to an $\mathrm{OO}$ nidus. Access to an $\mathrm{OO}$ or $\mathrm{OB}$ nidus or central aspect of any bony tumor is made with a coaxial bone biopsy set (e.g., Bonopty; AprioMed, Uppsala, Sweden) (- Fig. 9), and core biopsies are obtained as previously described ( - Fig. $2 d$, e). With malignant tumors treated with palliative intent, RFA is mainly targeted at the interface between the tumor and normal bone, where pain generates, followed by attempts at ablating the whole tumor. ${ }^{29,30}$ For soft tissue tumors, a coaxial system is used to reach the target, obtaining core biopsies, and subsequently the trocar is used as a cannula to
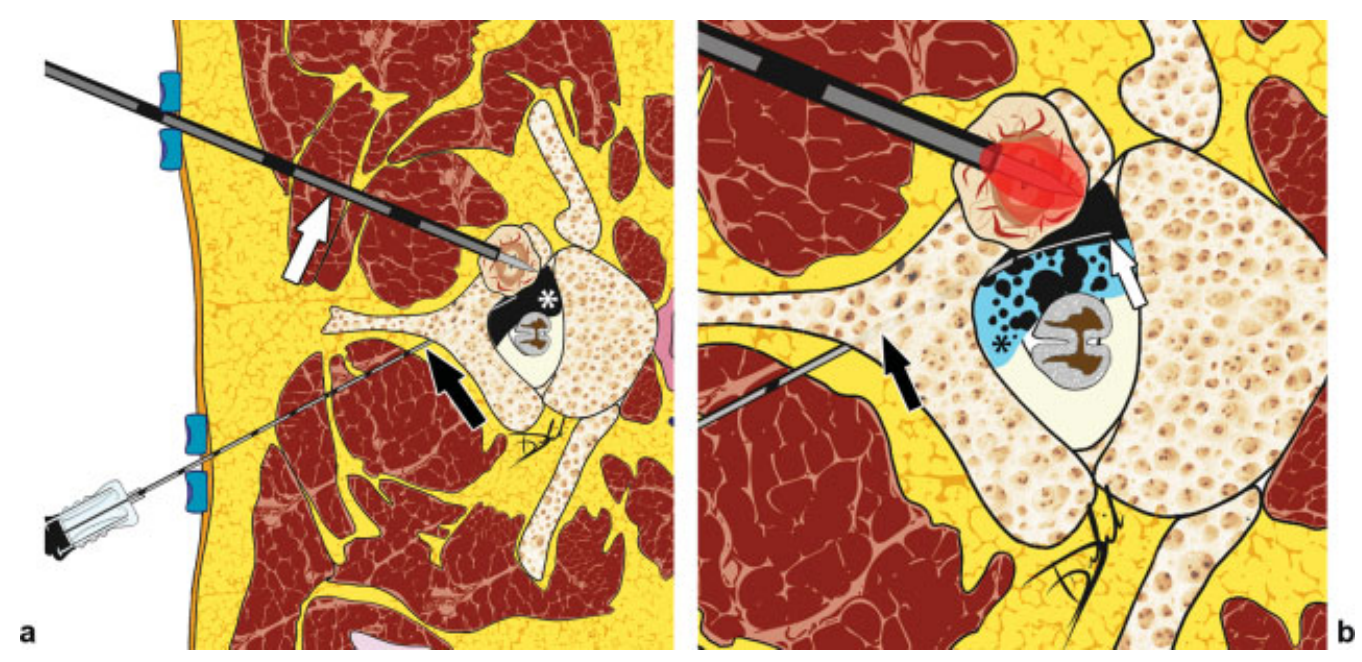

Fig. 7 Schematic of thermoprotective measures adopted for targeted radiofrequency ablation (RFA) of an osteoblastoma in the cervical spine. (a) Under computed tomography guidance, an 18 to $22 \mathrm{G}$ spinal needle is inserted into the epidural space interposed between the index tumor and critical structures. An 11 to $14 \mathrm{G}$ bone trocar is gently advanced into the central nidus of the tumor and the obturator replaced with the RFA electrode (white arrow). An interlaminar (black arrow) or transforaminal approach or even both may be adopted. The former approach is shown above, whereby the spinal needle is inserted through the interlaminar space and ligamentum flavum into the epidural space on the ipsilateral side to the index tumor. Gas/carbodissection using 2 to $5 \mathrm{~cm}^{3}$ carbon dioxide (white asterisk) is performed thereafter, creating an epidurogram upon injection. The operator may opt to position the patient in the lateral position (as shown here) to maintain a gas pocket in the nondependent distribution. In addition to outlining the epidural space, this measure opts to displace the cord and any neural structures away from the ablation zone. (b) Carbodissection may be coupled with additional continuous injection of cool/room temperature fluid (5\% dextrose in water in cases of RFA) through the same needle (typically at a rate of 1-2 mL/minute) while actively ablating (black asterisk). As an added precaution, when multiple ablations of a large lesion need to be performed, a thermocouple (white arrow) may also be inserted coaxially into the epidural space through an $18 \mathrm{G}$ spinal needle (black arrow). The sensor (white arrow) should be placed in the interface to monitor local temperatures and ensure they do not exceed the neurotoxic threshold $\left(45^{\circ} \mathrm{C}\right)$. 


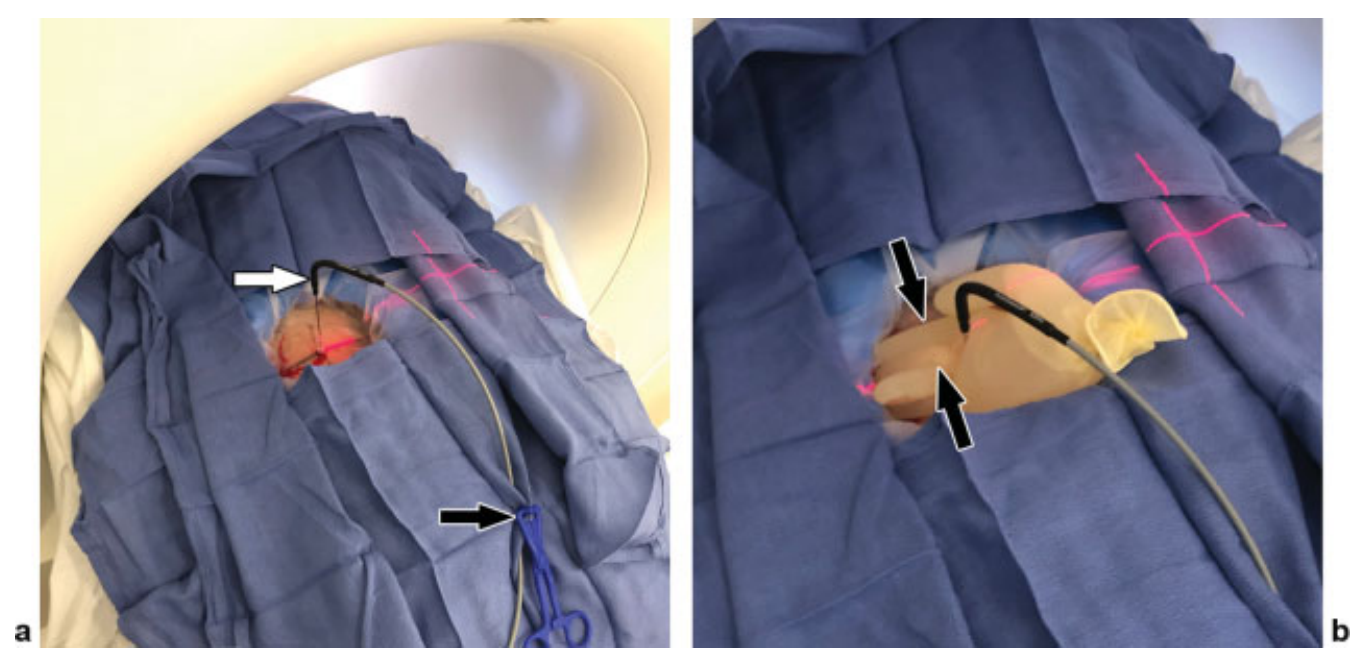

Fig. 8 Cryoablation dermal thermoprotective measures against frostbite. (a) The cryoprobe (white arrow) is inserted percutaneously into the lesion with magnetic resonance imaging guidance, and the connecting tube is supported with plastic forceps against the drape (black arrow) to minimize torque. (b) A latex-free surgical glove is filled with warm saline and placed in contact with the patient's skin with the probe interposed between the index and middle fingers (black arrows) throughout the duration of the procedure.

a, b
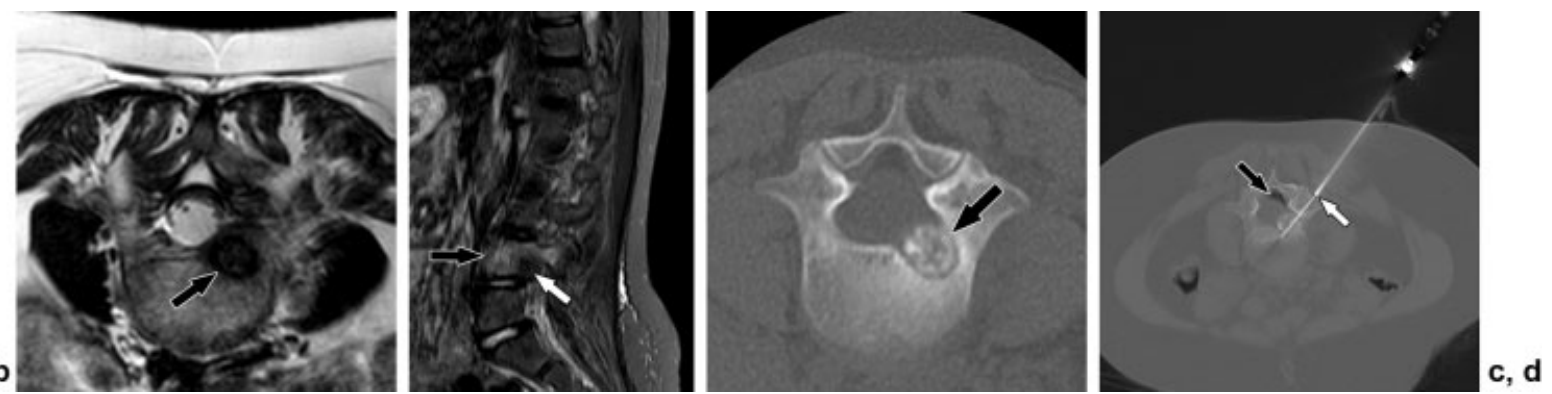

Fig. 9 Radiofrequency ablation of an osteoblastoma in the fourth lumbar vertebrae. (a) Axial T2-weighted image depicts a low signal (sclerotic), wellcircumscribed lesion in the posterior vertebral wall and pedicle of L4 (arrow). (b) Sagittal short tau inversion recovery demonstrates florid vertebral bone marrow edema (black arrow) and the sclerotic lesion (white arrow) resulting in thoracolumbar scoliosis. (c) Axial computed tomography illustrates the wellcircumscribed tumor and allows planning for thermoablation. (d) Following 14G coaxial (Bonopty; AprioMed, Uppsala, Sweden) transpedicular bone access and drilling to the center of the tumor, the radiofrequency probe is inserted and advanced until the active probe tip approximates the epicenter of the tumor nidus. The trocar is withdrawn to the cortex to prevent heat propagation along it (white arrow). An ablation protocol of six 3 -minute cycles of up to $90^{\circ} \mathrm{C}$ is performed incorporating carbodissection thermoprotective measures (black arrow).

guide the RF probe(s) to various aspects of the tumor. ${ }^{66}$ The 15 - to $20-\mathrm{cm} R F$ probes with 1 - to 2 -cm active tips are usually adopted to cover an ablation zone circumference of 1 to $2 \mathrm{~cm}$, respectively. More recently, active tips to cover up to $3 \mathrm{~cm}$ were developed by Boston Scientific (Spencer, IN, USA) radiotherapeutics. Once the planned needle position is reached, the introduced cannula is partially withdrawn over the electrode (by $\geq 1 \mathrm{~cm}$ ) to prevent heat propagation along the needle. ${ }^{60,67}$ Ablations are routinely performed for a total of 400 seconds ( 6.5 minutes) at a temperature of 60 to $90^{\circ} \mathrm{C}$. RF temperature is maintained at a maximum of $95^{\circ} \mathrm{C}$ and a maximum of two applications of 12-minute ablations per session. Cortical bone has an insulating effect, and approaches aiming at maximizing the distance between tumor and cortex should be considered where possible.

\section{Definitions of Technical and Clinical Success}

1. Successful thermoprotection application

2. Placement of the active tip within the nidus or center of a tumor
3. Full coverage of the entire tumor by the ablation area

4. Ablation performed according to the preplanned or manufacturer-defined ablation protocol

5. Ensure the correct temperature is achieved at the tip with even distribution when performing repeat ablations by monitoring needle performance (resistance, temperature, and watts) and exchanging for a new probe if thresholds are not met to ensure optimal ablation zones

6. Pain relief and weaning off the requirement for pain killers within 6 months of the procedure and/or involution of the tumor and reduction or complete resolution of spinal and neural compromise

7. Involution of the tumor and/or bone filling on subsequent imaging. In case of $\mathrm{OO}$ and $\mathrm{OB}$, sclerosis of the nidus and reduced vascularity should also be observed ${ }^{2,3,22}$

Established clinical applications of RFA include targeting the following:

- Benign (OO, OB, desmoid tumors, ${ }^{65}$ chondroblastoma, and $\mathrm{GCTs}^{68}$ ): Rosenthal et al first reported the use of RFA in the 
MSK system for the treatment of $00 .{ }^{69,70}$ OBs share histologic similarity to OOs, but the latter are reported to have a fourfold incidence over the former. ${ }^{22} \mathrm{OBs}$ are by definition larger (typically $\geq 1.5 \mathrm{~cm}$ ) requiring the use of simultaneous or consecutive RFA transducers to treat, thereby increasing the risk of recurrence and fractures. Procedures are mostly done under CT or MRI guidance. The alternative of three-dimensional (3D) fluoroscopy imaging has been advocated as an alternative to minimize radiation exposure $^{51}$ while allowing for real-time imaging of the tumor. Following RFA there is marked improvement in pain scores and ability to participate in both daily as well as sportsrelated activities. ${ }^{2}$ RFA has therefore been advocated as first-line therapy for spinal OO and OBs (- Fig. 9). ${ }^{2}$

- Malignant (skeletal metastasis, myeloma, soft tissue metastasis, and plasmacytomas): Combined RFA and cementoplasty offers safe, effective, and minimally invasive therapy for palliative treatment of painful neoplastic soft tissue and skeletal tumors, particularly metastatic lytic tumors ${ }^{71}$ associated with neoangiogenesis and mechanical instability. ${ }^{42,53,72}$ RFA was shown to be effective in the management of painful benign and malignant bone tumors ${ }^{70,73,74}$ as well as bone metastasis ${ }^{75}$ (- Fig. 2) with a curative intent in certain cohorts of patients, ${ }^{41,73}$ particularly with tumors $\leq 2 \mathrm{~cm}$ in size. ${ }^{48}$

- Neurovascular related to the musculoskeletal system: Used for palliative pain relief; targeting locoregional neural supply, neuromas (-Fig. 10), neuroendocrine metastases, hemangioendotheliomas, and intramuscular hemangiomata. ${ }^{76}$

\section{Cryoablation}

\section{Technique}

Extreme cold temperatures are applied to the tumor core to destroy cells and trigger apoptosis and focal sudden cellular ischemia. Gas used to trigger freezing is either argon or helium (both inert gases) delivered through small cryoprobes to induce rapid freezing and thawing of target tissues according to the Joule-Thompson effect, ${ }^{65}$ creating an ice ball at the tip of the probe that should be planned to be entirely within the tumor. Contrary to RFA, it is hypothesized that CA also stimulates a specific autologous antitumoral immune response, thus triggering regression of distant metastasis, ${ }^{77-79}$ although further research into this theory is warranted to better understand this mechanism and effects. Classically three cycles of freezing and thawing are performed. Procedures can be performed under US, CT, or MRI; however, MR guidance is preferred to monitor the ice ball and the neighboring structures ( $\mathbf{- F i g} \mathbf{5} \mathbf{b}$ and - Fig. $\mathbf{6 c}$ ) maximizing the benefits of the procedure by ensuring full coverage of the tumor while minimizing complications to surrounding vital structures. ${ }^{65,80}$

\section{Advantages of Cryoablation}

1. Better visualization and control of the region ablated and direct visualization of the cryoablation zone (ice ball) both on CT and MRI, allowing for better planning while avoiding surrounding nontarget structures, particularly nerves. ${ }^{49,50}$

2. Due to insulating effects of cortical bone, RFA is less favored in sclerotic metastases, whereas CA is equally favored in lytic, sclerotic, and mixed-type tumors. ${ }^{48,58}$

3. CA requires generally lower levels of anesthetic cover because cooling in itself provides a degree of anesthesia ("cryoanalgesia"). ${ }^{50}$

4. Due to its mechanism of action on the tumors, the electrical changes observed through current mediated effects affecting neural function are not observed during cryotherapy, thus reducing the risk of neural complications.

5. Cryoadhesional retraction away from vital structures: The ability to control freezing temperatures in each probe, while coalescing the ice ball formed, allows for setting the probes in close proximity to less freezing temperatures (reducing ice damage) followed by cryoadhesional retraction of the tumor en bloc, distancing it away from any vital structures before performing CA at full temperature settings. Upon thawing, structures retract again to their original position safely. This technique needs to be repeated in each freezing cycle but is inherently exclusive to CA and can improve the outcome of procedures.
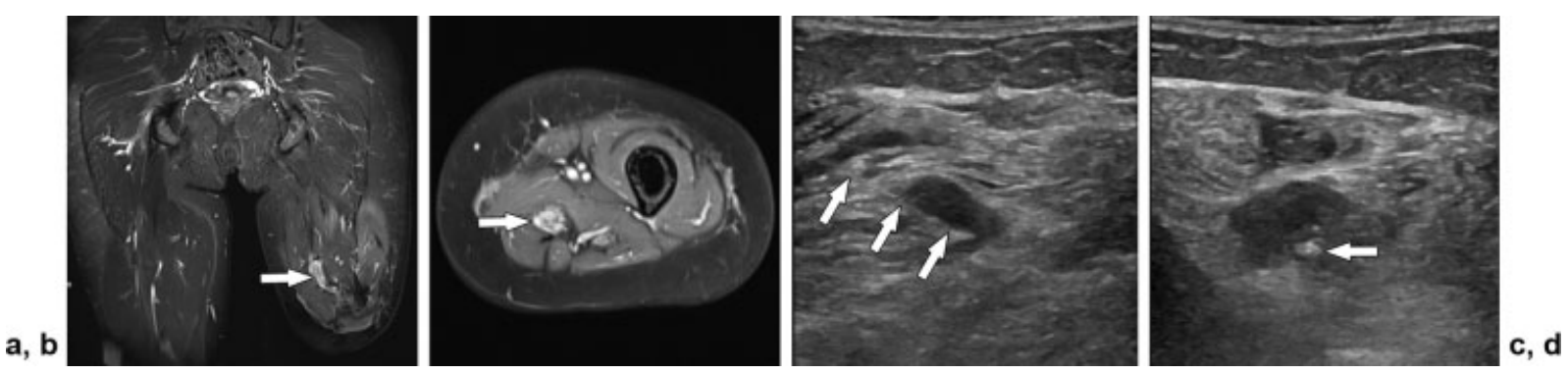

Fig. 10 Ultrasound (US)-guided radiofrequency ablation of a stump neuroma in a 47-year-old female patient with below-knee amputation causing severe pain when using her prosthetic limb. (a) Coronal and (b) axial short tau inversion recovery sequences demonstrate a large hyperintense stump neuroma (arrow). (c) US guidance with the patient in the prone position permits targeted local perineural infiltration of the hypoechoic neuroma with $8 \mathrm{~mL}$ bupivacaine hydrochloride ( $0.25 \%$ ) through the ablation needle (arrows). (d) Subsequently the needle is positioned into the epicenter of the neuroma and the stylet is replaced with the radiofrequency electrode (arrow). Three ablation cycles are performed at $90^{\circ} \mathrm{C}$ for 3 minutes each, and the patient reported $>50 \%$ improvement of pain on mobilizing in her prosthesis at 3-month follow-up. 
6. CA is compatible with metallic implants and cardiac stimulators.

Established clinical applications of CA include targeting the following:

- Benign: Extra-abdominal desmoid tumors, ${ }^{65} \mathrm{OO}$ (-Fig. 5), $\mathrm{OB},{ }^{81} \mathrm{ABC}$ (-Fig. 6), primary bone tumors, neuromata and AVMs, ${ }^{82,83}$ and chondroblastoma. ${ }^{84}$

- Malignant: Skeletal metastasis (particularly osteoblastic and sclerotic; - Fig. 11), myeloma, soft tissue metastasis, plasmacytomas, and in-transit melanoma metastases. ${ }^{85}$ It provides immediate and short-term pain relief, with promising results for long-term pain relief and locoregional control. ${ }^{41,65}$ Outcomes are best if there are fewer than three tumors and each tumor is $<3 \mathrm{~cm}$ in size. 57,65 CA can be performed with curative or palliative intent, depending on disease burden.

- Neurovascular: Palliative; targeting locoregional neural supply, neuroendocrine metastases, hemangioendotheliomas, intramuscular hemangiomata, and benign neural tumors such as Morton's neuroma, which interestingly represent non-neoplastic perineural fibrosis of the digital plantar nerve and are histologically therefore pseudotumors.

\section{Microwave Ablation}

\section{Technique}

Procedures are mostly performed under CT or MRI. A 16G ablation needle (e.g., Medwaves, San Diego, CA) is introduced centrally into the hypervascularized nidus or center of tumors, depicted on preprocedural imaging, ideally a 3D DCE-MRI when possible. MWA is performed at $16 \mathrm{~W}$, $915 \mathrm{MHz}, 80^{\circ} \mathrm{C}$. Ablation time depends on the diameter of the tumor (45-160 seconds). After ablation, the needle is withdrawn and sterile dressings are applied. During the procedure, pre- and post- DCE-MRI data sets measure signal intensities, plasma flow $(\mathrm{mL} / 100 \mathrm{~mL} /$ minute $)$, mean volume of distribution $(\mathrm{mL} / 100 \mathrm{~mL})$, and mean transit time (per second) using a software tool for quantitative MRI perfusion analysis (e.g., UMMPerfusion, OpossUMM, Germany). ${ }^{20}$ Application of multiple antennae simultaneously may help achieve large nearly spherical ablation zones, improving control and allowing the radiologist to mold the zone to the tumor size and shape. ${ }^{86}$

Advantages: MWA can induce effective coagulation faster than other ablation techniques, ${ }^{87}$ extend deeper with reduced inherent resistance to osseous impedance of energy, reducing the overall procedure time and improving results with deeper and larger lesions when compared with other
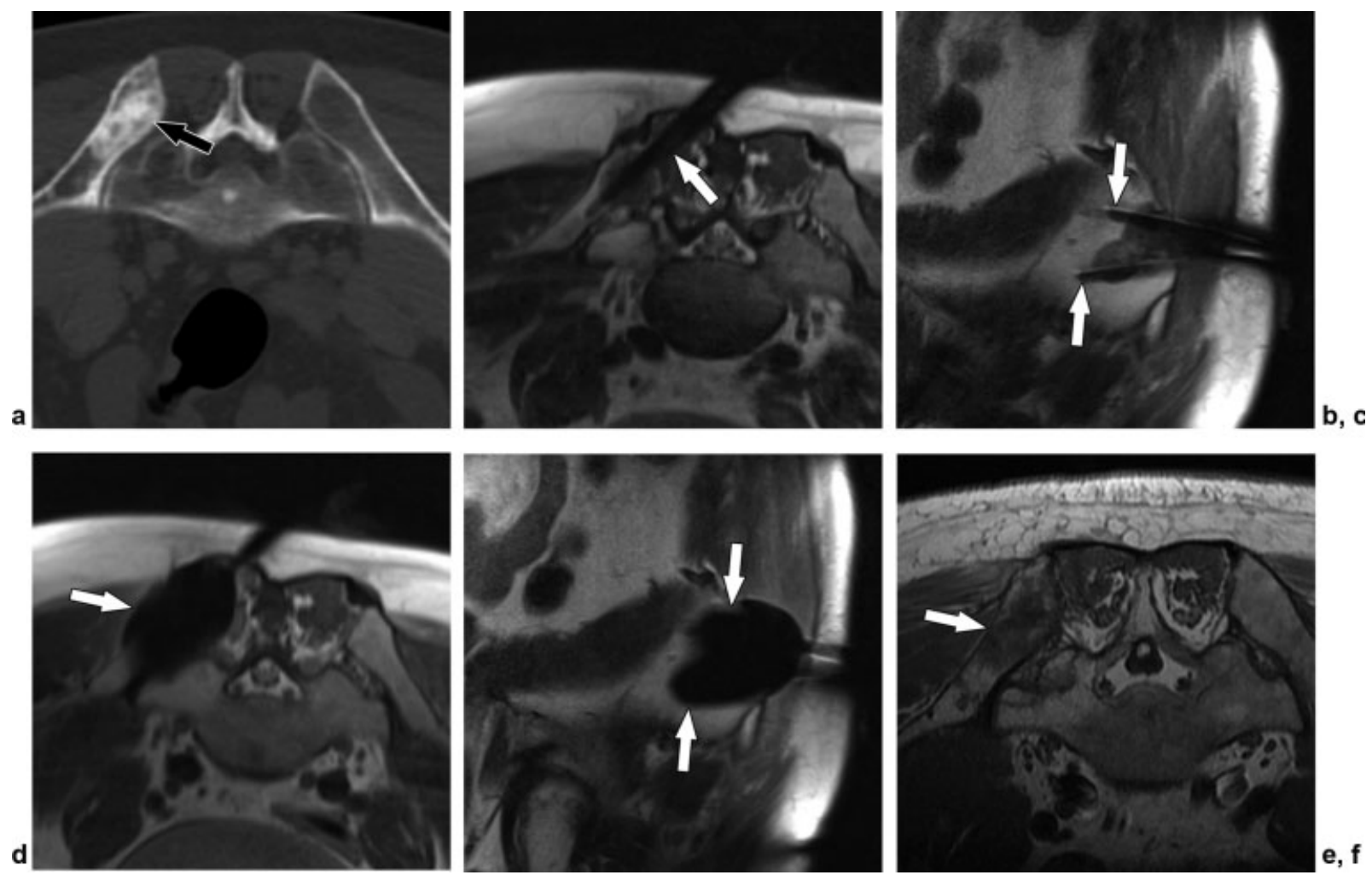

Fig. 11 Cryoablation guided by magnetic resonance imaging (MRI) cryoablation of a sclerotic, osseous prostate cancer metastasis in a 70-year-old man with oligometastatic disease. (a) Baseline axial, prone computed tomography image demonstrates the extent of the sclerotic lesion (arrow) permitting preprocedural planning. (b, c) Dual osseous access with two 13G MRI-compatible bone trocar drill systems (b, arrow) using a posterior transiliac approach to ensure a large enough ice ball and ablation zone to cover all aspects of the metastasis. The tips of the cryoablation probes pass beyond the anterior margin of the metastasis (c, arrows). (d, e) MRI monitoring of the ice balls (arrows) using an axial accelerated intermediate-weighted turbo spin-echo pulse sequence during multiple freeze-thaw cycles. With this technique, the two ice balls coalesce to form a "giant ice ball" that occupies the entire lesion. (f) At 12-month follow-up, axial T1-weighted MRI of the metastasis demonstrates stable appearances (arrows), consistent with local tumor control. The patient's pain reduced from a visual analog scale score of 8 of 10 preprocedure to 2 of 10 at a 1-year postprocedure. 
ablation techniques. MWA penetration is also higher, rendering it more immune to heat-sink and charring buildup effects when compared with other ablation techniques. ${ }^{88}$

Disadvantages: Most manufacturers issue guidelines calibrated (ablation time and watts) for soft tissue tumors ${ }^{87}$ (regardless of histology and local tissue properties). Therefore further research is needed into optimizing parameters for bone tumors and variations depending on the tumor matrix. The ability to perform real-time evaluations (such as with RFA and CA) is required.

Established clinical applications of MWA include targeting the following:

- Benign 00: MWA can reliably treat 00, with no recognized complications or recurrence, ${ }^{19,20}$ with statistically significant reduction in reported pain scores and overall volume of the tumors, enabling rapid and effective locoregional healing in this young patient cohort.

- Malignant (skeletal metastasis, multiple myeloma, soft tissue metastasis, and plasmacytomas): Recent studies demonstrate good results for MWA and cementoplasty, particularly with low-volume and oligometastatic disease loads. ${ }^{87}$

\section{Interstitial Laser Ablation}

\section{Technique}

Optical fibers are inserted into tumors, and between 400 and 3,000 J are delivered as continuous monochromatic, collimated, and coherent energy pulse(s)/wave(s). The advantages of ILA are precision delivery of energy into a tumor, offering precise targeting of lesions and minimal associated damage to surrounding structures ${ }^{34}$ while alleviating the need (and cost) of thermoprotection with extraspinal bone procedures. ${ }^{34}$ The costs of disposable optical fibers are low, and so departmental running costs are fairly reasonable. ILA is MRI compatible and can be used safely while actively monitoring the lesion and surrounding structures with MR guidance. The overlying skin is intact, and so the outcomes are more aesthetically favorable; healing is simpler and faster. Ease and safety of repeating the procedure presents opportunities to address tumor recurrence and/or progression.
Established clinical applications of laser include targeting the following:

- Benign: OO (-Fig. 12), OB, and vascular anomalies related to the MSK system, particularly in the spine, ${ }^{34,36,47,60,76}$ including hemangioendotheliomas that are otherwise complicated by profound bleeding due to developing hemangioma thrombocytopenia syndrome. ${ }^{76}$ Precision and fast delivery of energy within a small ablation zone renders ILA a safe and reliable option in patients presenting with vascular anomalies that have failed conventional therapies, with minimal side effects. This is relevant because they inherently reside near neural structures that would otherwise be vulnerable to ablation complications.

- Malignant: For MSK tumors, ILA remains largely performed in a subclinical research capacity. ${ }^{89}$

\section{Nonpercutaneous Thermal Ablation Procedures}

\section{Magnetic Resonance Imaging-Guided High-Intensity Focused Ultrasound Ablation}

\section{Technique}

MRg-HIFU focuses noninvasive delivery of 4 to $400 \mathrm{MHz}$ of US waves via a probe to deliver 65 to $85^{\circ} \mathrm{C}$ thermal ablation, resulting in coagulative necrosis with both pain palliation and locoregional tumor control. This technique has been applied thus far to bladder, prostate, and uterine tumors, although recent case series were published of early results trialing its utility in OOs $^{90,91}$ and bone metastasis ${ }^{91-94}$ (-Fig. 13 and - Fig. 14, respectively). If performed in weight-bearing bones, it should be combined with stabilization procedures (-Table 2 ). It remains a noninvasive intervention (unless combined with percutaneous procedures such as cementoplasty).

Established clinical applications of MRg-HIFU include targeting the following:

- Benign: $0^{95}$ and $\mathrm{OB}$ can be successfully treated with MRg-HIFU with complete pain relief and no morbidity, despite radiologic persistence of vascularity within the tumor nidus on follow-up imaging. ${ }^{90,91}$ Similarly, MRg-
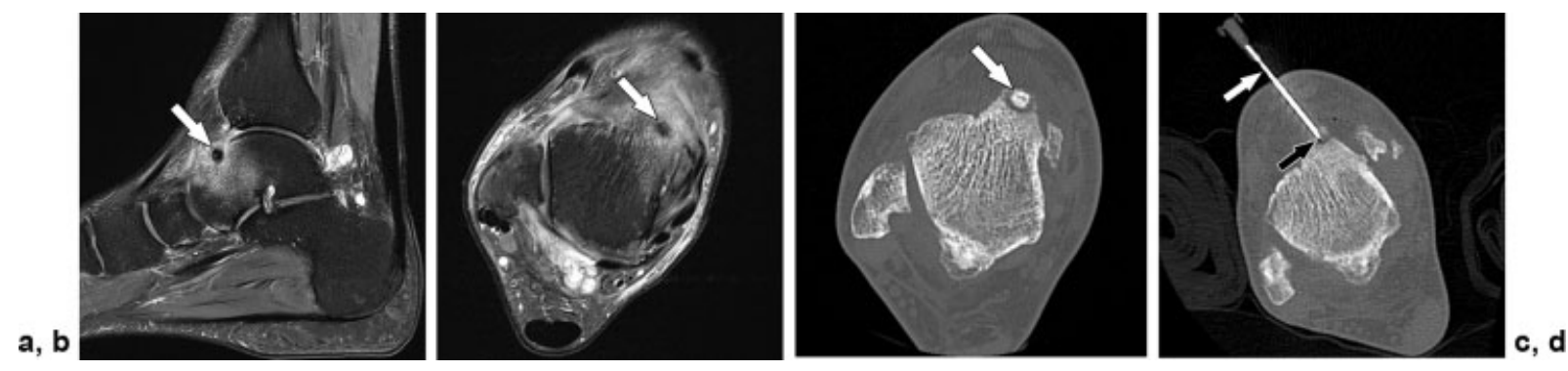

Fig. 12 Interstitial laser ablation (ILA) guided by computed tomography (CT) of a talar osteoid osteoma in a 21-year-old man. Baseline (a) sagittal and (b) axial short tau inversion recovery magnetic resonance imaging sequences delineate a sclerotic low signal nidus (white arrows) surrounded with florid bone marrow edema and reactive synovitis in the tibiotalar joint. (c) Preprocedural axial CT image allows appreciation of the size of the sclerotic nidus (white arrow) and permits ablation planning. Following multidisciplinary tumor board discussion, ILA was recommended over surgery. (d) Intraprocedural axial CT demonstrates a direct coaxial needle approach (white arrow) into the center of the nidus, with replacement of the needle obturator with the optical fiber, seen protruding into the epicenter of the nidus (black arrow). Gas locules are appreciable as a result of the tissue cauterization. 

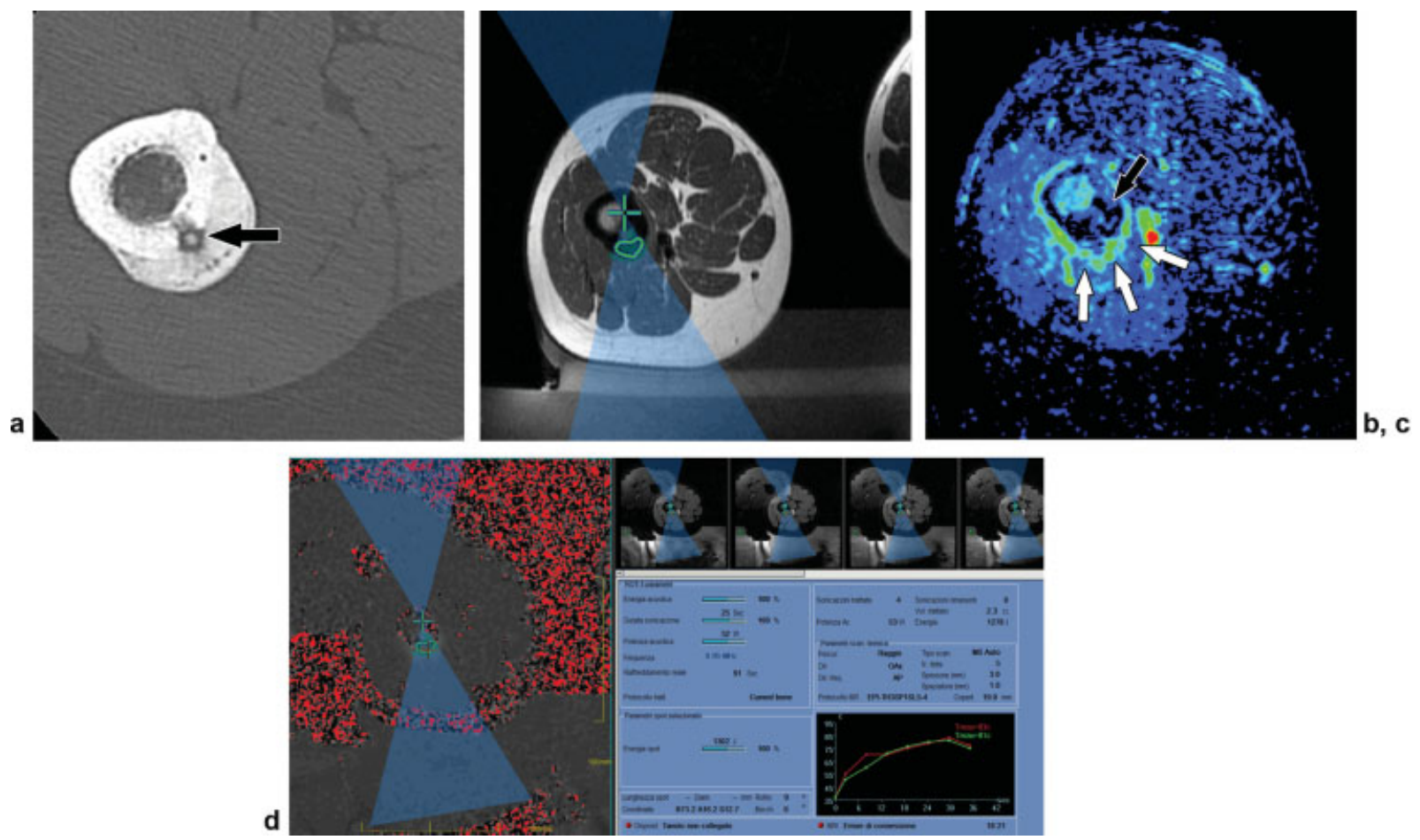

Fig. 13 Curative treatment of a painful $\mathrm{OO}$ (visual analog scale [VAS], 6/10) in a 25-year-old man by magnetic resonance-guided high-frequency focused ultrasound (MRg-HIFU). (a) Computed tomography of the right femoral diaphysis demonstrates a central sclerotic nidus (arrow), with a lucent rim and surrounding sclerosis and periosteal thickening typical for an OO. (b) Procedural planning: the patient is lying prone on the MRg-HIFU bed, with the targeted thigh positioned on a gel pad, surrounded by degassed water. Such steps as well as other tools (e.g., water bags) help optimize the size and clearance of the interface window, minimizing interference to the ultrasound beam. Note target color mapping: the light blue hourglass-like area shows the ultrasound beam path. The green cross is centered on the targeted focus. The green circle marks the spot of expected energy delivery to bone (and should be centered on the lesion). (c) Dynamic contrast enhancement map after treatment demonstrating soft tissue periosteal edema (white arrows) and devascularization of the central nidus in (d) (black arrow). (d) Framed screen shots of the HIFU workstation after completing a sonication; on the left temperature map, with expected ablated area after sonication (and overlapping ultrasound beam, focus, and sonication area); on the right, parameters of sonication (including power, frequency, sonication time, cooling time, expected energy delivery), with the temperature graph on bottom right showing temperature progression during the sonication (temperature ${ }^{\circ} \mathrm{C} \times$ time $s$ ) at the checked spot set (orange cross on the temperature map on the left). At 3 months, postprocedure pain had resolved with VAS recorded as 0 of 10.

HIFU was successfully used for targeting extra-abdominal desmoid tumors. ${ }^{96}$

- Malignant: MRg-HIFU has been applied to treating metastasis and/or multiple myeloma, plasmacytoma, and other focal myeloproliferative disorders: potential radical treatment of bone metastasis has also been reported with
MRg-HIFU, with 33.3\% complete curative or partial response observed in the literature. ${ }^{93,94,97}$

Best results are achieved with MRg-HIFU in these situations:
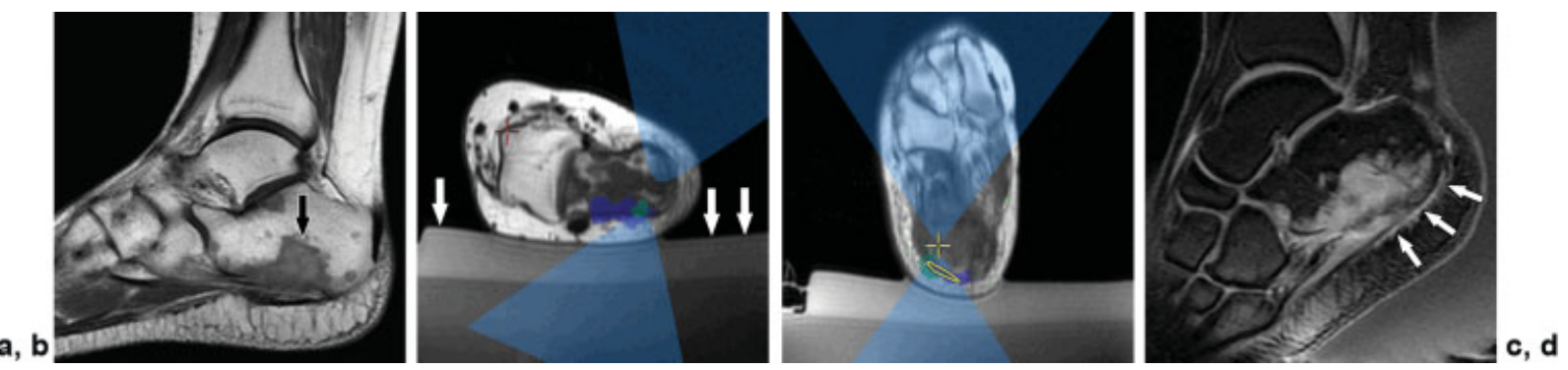

Fig. 14 Palliative treatment of a painful breast cancer bone metastasis (VAS 8/10) in a 52-year-old woman by magnetic resonance-guided highfrequency focused ultrasound (MRg-HIFU). (a) Sagittal T1-weighted magnetic resonance imaging demonstrates a focal metastatic deposit (black arrow) in the calcaneus. (b, c) Multiplanar positioning on the MRg-HIFU bed for treating both aspects of the tumor (foot positioned on a gel pad for coupling; white arrows). The green area denotes the next planned ablation zone after the current sonication (based on temperatures achieved over the area). The blue area represents the ablation zones from previous sonications. The light blue hourglass-like shape represents the ultrasound beam path. (d) Postcontrast images of the lesion as a result of ablation. Note the rim of absent enhancement following gadolinium injection (white arrows) of the periosteum, cortex, and subcortex, with mild circumferential soft tissue edema surrounding the lesion. This was associated with significant pain reduction and improvement in the quality of life of the patient for several months with VAS lowered from 8 of 10 (preprocedural) to 3 of 10 at 2 weeks postprocedure. 
Table 2 Armamentarium of interventional techniques

\begin{tabular}{|c|c|c|c|c|c|}
\hline \multicolumn{6}{|c|}{ Interventional radiology techniques } \\
\hline $\begin{array}{l}\text { Aim of the } \\
\text { technique }\end{array}$ & \multicolumn{2}{|c|}{$\begin{array}{l}\text { Ablation techniques (inducing tumoral } \\
\text { necrosis) }\end{array}$} & \multicolumn{2}{|c|}{ Mechanical stabilization techniques } & \multirow{2}{*}{$\begin{array}{c}\begin{array}{c}\text { Minimizing blood } \\
\text { loss }\end{array} \\
\text { Vascular } \\
\text { embolization of } \\
\text { vessels feeding the } \\
\text { tumors }\end{array}$} \\
\hline Mode of therapy & $\begin{array}{l}\text { Chemical-based } \\
\text { ablations }\end{array}$ & $\begin{array}{c}\text { Energy-based } \\
\text { ablations } \\
\text { (thermoablation) }\end{array}$ & $\begin{array}{l}\text { Cavity filling } \\
\text { postablation }\end{array}$ & $\begin{array}{l}\text { Metalwork inser- } \\
\text { tion for mechanical } \\
\text { reinforcement }\end{array}$ & \\
\hline \multirow[t]{5}{*}{$\begin{array}{l}\text { Examples (can be } \\
\text { used in conjunction } \\
\text { as combined proce- } \\
\text { dures or separately } \\
\text { as independent } \\
\text { procedures) }\end{array}$} & Ethanol & RFA & Osteosynthesis & Stents & \multirow{6}{*}{$\begin{array}{l}\text { Particularly useful } \\
\text { with vascular lesions } \\
\text { that have increased } \\
\text { risk of blood loss } \\
\text { when attempting } \\
\text { any interventions } \\
\text { (minimally invasive } \\
\text { or surgical) to treat } \\
\text { the tumor (e.g., in- } \\
\text { clude renal and thy- } \\
\text { roid metastasis, } \\
\text { locally advanced gi- } \\
\text { ant cell tumors) }\end{array}$} \\
\hline & Doxycycline & $C A$ & $\begin{array}{l}\text { Cementoplasty } \\
\text { (PMMA) including } \\
\text { free-hand injection, } \\
\text { vertebroplasty, } \\
\text { kyphoplasty }\end{array}$ & $\begin{array}{l}\text { Augmentation } \\
\text { devices }\end{array}$ & \\
\hline & & MWA & & Screws & \\
\hline & $\begin{array}{l}\text { Polidocanol (deter- } \\
\text { gent sclerosant) }\end{array}$ & LA & & K-wires & \\
\hline & $\begin{array}{l}\text { STS (detergent } \\
\text { sclerosant) }\end{array}$ & MRg-HIFU & & & \\
\hline $\begin{array}{l}\text { Other techniques } \\
\text { not yet applied in } \\
\text { musculoskeletal } \\
\text { settings }\end{array}$ & & $\begin{array}{l}\text { Other energy-based } \\
\text { ablations: IRE, IRE } \\
\text { ablation, or H-FIRE }\end{array}$ & & & \\
\hline
\end{tabular}

Abbreviations: CA, cryoablation; H-FIRE, high-frequency irreversible electroporation; IRE, irreversible electroporation; LA, laser ablation; MRg-HIFU, magnetic resonance-guided high-frequency ultrasound; MWA, microwave ablation; PMMA, polymethylmethacrylate; RFA, radiofrequency ablation; STS, sodium tetradecyl sulfate.

1. Flat bones, with thin cortices such as the iliac bone and scapula.

2. Patients with low body mass index to reduce the distance between the skin surface and index lesion.

3. Low-volume disease load.

4. Lesions are situated between $1 \mathrm{~cm}$ and $12 \mathrm{~cm}$ from the skin's surface. Due to limitations of effectively targeting deep lesions, due to poor penetrability of US waves, lesions with depth $>12 \mathrm{~cm}$ are considered nontargetable. $^{92}$ Lesions situated $<1 \mathrm{~cm}$ from skin have increased risk of skin burns.

5. Vital structures requiring thermoprotection lie outside the US, even if active thermoprotection is possible, because it is less reliable in the field.

6. Thin cortices or soft tissue lesions. Cortical bone acts as an insulator; thus MRg-HIFU is unsuitable in patients where the lesion is surrounding by thick cortical bone. ${ }^{92}$

\section{Nonthermal Energy Ablation Techniques}

The nonthermal energy ablation techniques include irreversible electroporation (IRE or IRE ablation). ${ }^{15}$ This is not yet used in MSK settings and is not part of our practice(s). However, IRE has proven its benefits in targeting renal, brain, pancreatic, liver, and vascular smooth muscle tumors as well as in ablating other structures such as nerves, achieving sympathetic nerve denervation for managing malignant hypertension. ${ }^{98,99}$ IRE has wit- nessed several advances in its underlying technology in recent years that has increased its efficacy and safety profile. As a result, its range of applications has broadened, treating various tumors as well as in delivery of chemotherapeutic agents, thereby enhancing their action..$^{98,100}$

\section{Conclusion}

Image-guided MSK interventions offer safe, effective, and minimally invasive alternatives to conventional invasive therapies used to treat soft tissue and bone tumors. The aim of offering these procedures can either be curative, local tumor control, or palliative depending on the patient's comorbidities, previous therapies, and prognosis as well as the patient's choice. ${ }^{101}$ They are particularly useful in young patients to minimize damage to surrounding structures or in patients where other treatment options have been exhausted or carry high morbidity and mortality rates.

Understanding the patient's history at presentation and the imaging characteristics of tumors enables accurate diagnosis and timely management. Knowledge of the current repertoire of image-guided interventional oncologic ablation procedures, their indication, contraindications, as well as their benefits and potential associated comorbidities, plays a pivotal role in appropriate patient referral to specialized radiologists who can offer these procedures to patients in a timely manner. 


\section{Conflict of Interest}

Jan Fritz, MD, PhD, DABR, RMSK received institutional research support from Siemens Healthcare USA, DePuy, Zimmer, Microsoft, and BTG International; scientifically advised Siemens Healthcare USA, GE Healthcare Technologies, BTG International, ImageBiopsy Lab, Mirata Pharmaceuticals, Synthetic MR, and Boston Scientific; and has shared patents with Siemens Healthcare and Johns Hopkins University.

\section{References}

1 Gangi A, Tsoumakidou G, Buy X, Quoix E. Quality improvement guidelines for bone tumour management. Cardiovasc Intervent Radiol 2010;33(04):706-713

2 Beyer T, van Rijswijk CSP, Villagrán JM, et al. Correction to: European multicentre study on technical success and long-term clinical outcome of radiofrequency ablation for the treatment of spinal osteoid osteomas and osteoblastomas. Neuroradiology 2019;61(08):943

3 Weber MA, Sprengel SD, Omlor GW, et al. Clinical long-term outcome, technical success, and cost analysis of radiofrequency ablation for the treatment of osteoblastomas and spinal osteoid osteomas in comparison to open surgical resection. Skeletal Radiol 2015;44(07):981-993

4 Sugiyama H, Omonishi K, Yonehara S, et al. Characteristics of benign and malignant bone tumors registered in the Hiroshima Tumor Tissue Registry, 1973-2012. JBJS Open Access 2018;3(02): e0064

5 Franchi A. Clinical cases in mineral and bone epidemiology and classification of bone tumors. Metabolism 2012;9(02):92-95

6 Surveillance, Epidemiology and End Results (SEER) Program SEER Cancer Statistics Review (CSR) 1975-2016. Updated February 14, 2020. Available at: https://seer.cancer.gov/archive/csr/ 1975_2016/2020

7 Cancer Research UK Registry Soft tissue sarcoma statistics Available at: https://www.cancerresearchuk.org/health-professional/ cancer-statistics/statistics-by-cancer-type/soft-tissue-sarcoma

8 Cancer Research UK Registry Bone sarcoma statistics Available at: https://www.cancerresearchuk.org/health-professional/cancertatistics/statistics-by-cancer-type/bone-sarcoma\#heading-Zero

9 Isaac A, Dalili D, Dalili D, Weber M-A. State-of-the-art imaging for diagnosis of metastatic bone disease [in German]. Radiologe 2020; March 24 (Epub ahead of print)

10 Vilanova JC. WHO classification of soft tissue tumors. In: Vanhoenacker FM, Parizel PM, Gielen JL, eds. Imaging of Soft Tissue Tumors. Cham, Switzerland: Springer; 2017:187-196

11 WHO Classification of Tumours Editorial Board WHO Classification of Tumours. 5th ed. Vol 3. Lyon, France: WHO; 2020

12 Ishida Y, Qiu D, Maeda M, et al. Secondary cancers after a childhood cancer diagnosis: a nationwide hospital-based retrospective cohort study in Japan. Int J Clin Oncol 2016;21(03): 506-516

13 Joo MW, Kang YK, Ogura K, et al. Post-radiation sarcoma: a study by the Eastern Asian Musculoskeletal Oncology Group. PLoS One 2018;13(10):e0204927

14 Hasan K, Nguyen DM, Conway SA. Benign bone tumors when they coexist with common orthopaedic conditions. J Knee Surg 2019;32(04):296-304

15 Ahmed M, Solbiati L, Brace CLInternational Working Group on Image-guided Tumor Ablation Interventional Oncology Sans Frontières Expert Panel Technology Assessment Committee of the Society of Interventional Radiology Standard of Practice Committee of the Cardiovascular and Interventional Radiological Society of Europe., et al; . Image-guided tumor ablation: standardization of terminology and reporting criteria-a 10-year update. Radiology 2014;273(01):241-260
16 Lalam R, Bloem JL, Noebauer-Huhmann IM, et al. ESSR Consensus Document for Detection, Characterization, and Referral Pathway for Tumors and Tumorlike Lesions of Bone. Semin Musculoskelet Radiol 2017;21(05):630-647

17 Papakonstantinou O, Isaac A, Dalili D, Noebauer-Huhmann IM. T2-weighted hypointense tumors and tumor-like lesions. Semin Musculoskelet Radiol 2019;23(01):58-75

18 Afonso PD, Isaac A, Villagrán JM. Chondroid tumors as incidental findings and differential diagnosis between enchondromas and low-grade chondrosarcomas. Semin Musculoskelet Radiol 2019; 23(01):3-18

19 Kostrzewa M, Diezler P, Michaely H, et al. Microwave ablation of osteoid osteomas using dynamic MR imaging for early treatment assessment: preliminary experience. J Vasc Interv Radiol 2014; 25(01):106-111

20 Kostrzewa M, Henzler T, Schoenberg SO, Diehl SJ, Rathmann N. Clinical and quantitative MRI perfusion analysis of osteoid osteomas before and after microwave ablation. Anticancer Res 2019;39(06):3053-3057

21 Gondim Teixeira PA, Leplat C, Chen B, et al. Contrast-enhanced 3T MR perfusion of musculoskeletal tumours: T1 Value heterogeneity assessment and evaluation of the influence of T1 estimation methods on quantitative parameters. Eur Radiol 2017;27 (12):4903-4912

22 Kintzelé L, Brandelik SC, Wuennemann F, et al. MRI patterns indicate treatment success and tumor relapse following radiofrequency ablation of osteoblastoma. Int J Hyperthermia 2020; 37(01):274-282

23 Khodarahmi I, Isaac A, Fishman EK, Dalili D, Fritz J. Metal about the hip and artifact reduction techniques: from basic concepts to advanced imaging. Semin Musculoskelet Radiol 2019;23(03): e68-e81

24 Sonnow L, Gilson WD, Raithel E, Nittka M, Wacker F, Fritz J. Instrument visualization using conventional and compressed sensing SEMAC for interventional MRI at 3T. J Magn Reson Imaging 2018;47(05):1306-1315

25 Romu T, Elander L, Leinhard OD, et al. Characterization of brown adipose tissue by water-fat separated magnetic resonance imaging. J Magn Reson Imaging 2015;42(06):1639-1645

26 Cazzato RL, Garnon J, De Marini P, et al. French multidisciplinary approach for the treatment of MSK tumors. Semin Musculoskelet Radiol 2020;24(03):310-322

27 Burke MC, Garg A, Youngner JM, Deshmukh SD, Omar IM. Initial experience with dual-energy computed tomography-guided bone biopsies of bone lesions that are occult on monoenergetic CT. Skeletal Radiol 2019;48(04):605-613

28 Dalili D, Isaac A, Rashidi A, Åström G, Fritz J. Image-guided sports medicine and musculoskeletal tumor interventions: a patientcentered model. Semin Musculoskelet Radiol 2020;24(03): 290-309

29 Gennaro N, Sconfienza LM, Ambrogi F, Boveri S, Lanza E. Thermal ablation to relieve pain from metastatic bone disease: a systematic review. Skeletal Radiol 2019;48(08):1161-1169

30 Kurup AN, Callstrom MR. Expanding role of percutaneous ablative and consolidative treatments for musculoskeletal tumours. Clin Radiol 2017;72(08):645-656

31 Kaptan MA, Acu B, Öztunalı Ç, Çalışır C, İnan U, Bilgin M. Correlation of 3-T MRI and CT findings with patient symptoms and treatment outcome in radiofrequency ablation of osteoid osteoma. Acta Orthop Traumatol Turc 2019;53(04):239-247

32 Moon E, Tam MDBS, Kikano RN, Karuppasamy K. Prophylactic antibiotic guidelines in modern interventional radiology practice. Semin Intervent Radiol 2010;27(04):327-337

33 Vari A, Gangi A. Anesthesia practices for interventional radiology in Europe. Cardiovasc Intervent Radiol 2017;40(06):803-813

34 Gangi A, Alizadeh H, Wong L, Buy X, Dietemann JL, Roy C. Osteoid osteoma: percutaneous laser ablation and follow-up in 114 patients. Radiology 2007;242(01):293-301 
35 Fritz J, Dellon AL, Williams EH, Belzberg AJ, Carrino JA. 3-Tesla high-field magnetic resonance neurography for guiding nerve blocks and its role in pain management. Magn Reson Imaging Clin N Am 2015;23(04):533-545

36 Gangi A, Buy X. Percutaneous bone tumor management. Semin Intervent Radiol 2010;27(02):124-136

37 Shiels WE II, Mayerson JL. Percutaneous doxycycline treatment of aneurysmal bone cysts with low recurrence rate: a preliminary report. Clin Orthop Relat Res 2013;471(08):2675-2683

38 Tessari L, Cavezzi A, Frullini A. Preliminary experience with a new sclerosing foam in the treatment of varicose veins. Dermatologic Surg 2001;27(01):58-60

39 Choi WK, Bailey CR, Fritz J, Weiss CR. MR-guided sclerotherapy for the treatment of low-flow vascular malformations. Top Magn Reson Imaging 2018;27(03):153-161

40 Waikakul S, Asavamongkolkul A, Phimolsarnti R. Use of warm Ringer's lactate solution in the management of locally advanced giant cell tumor of bone. Int J Clin Oncol 2016;21(01):177-185

41 Luigi Cazzato R, Auloge P, De Marini P, et al. Percutaneous imageguided ablation of bone metastases: local tumor control in oligometastatic patients. Int J Hyperthermia 2018;35(01): 493-499

42 Callstrom MR, Dupuy DE, Solomon SB, et al. Percutaneous imageguided cryoablation of painful metastases involving bone: multicenter trial. Cancer 2013;119(05):1033-1041

43 Choi D, Crockard A, Bunger CGlobal Spine Tumor Study Group. , et al; . Review of metastatic spine tumour classification and indications for surgery: the consensus statement of the Global Spine Tumour Study Group. Eur Spine J 2010;19(02):215-222

44 Dalili D, Isaac A, Cazzato RL, et al. Interventional techniques for bone and musculoskeletal soft tissue tumors: current practices and future directions. Part 2: stabilization. Semin Musculoskelet Radiol 2020

45 Zoccali C, Teori G, Salducca N, Di Paola B, Adriani E. Arthroscopic guided biopsy and radiofrequency thermoablation of a benign neoplasm of the tibial spines area: a treatment option. BMC Musculoskelet Disord 2012;13(01):52

46 Li D, Madoff DC. Incorporating quality of life metrics in interventional oncology practice. Semin Intervent Radiol 2017;34 (04):313-321

47 Cazzato RL, Auloge P, De Marini P, et al. Spinal tumor ablation: indications, techniques, and clinical management. Tech Vasc Interv Radiol 2020;23(02):100677

48 Cazzato RL, Palussière J, Auloge P, et al. Complications following percutaneous image-guided radiofrequency ablation of bone tumors: a 10-year dual center experience. Radiology 2020;296 (01):227-235

49 Kurup AN, Schmit GD, Morris JM, et al. Avoiding complications in bone and soft tissue ablation. Cardiovasc Intervent Radiol 2017; 40(02):166-176

50 Kurup AN, Morris JM, Schmit GD, et al. Neuroanatomic considerations in percutaneous tumor ablation. Radiographics 2013;33 (04):1195-1215

51 Ankory R, Kadar A, Netzer D, et al. 3D imaging and stealth navigation instead of CT guidance for radiofrequency ablation of osteoid osteomas: a series of 52 patients. BMC Musculoskelet Disord 2019;20(01):579

52 Lipton A, Uzzo R, Amato RJ, et al. The science and practice of bone health in oncology: managing bone loss and metastasis in patients with solid tumors. J Natl Compr Canc Netw 2009;7 (Suppl 7):S1-S29; quiz S30

53 Lane MD, Le HBQ, Lee $S$, et al. Combination radiofrequency ablation and cementoplasty for palliative treatment of painful neoplastic bone metastasis: experience with 53 treated lesions in 36 patients. Skeletal Radiol 2011;40(01):25-32

54 Littrup PJ, Bang HJ, Currier BP, et al. Soft-tissue cryoablation in diffuse locations: feasibility and intermediate term outcomes. J Vasc Interv Radiol 2013;24(12):1817-1825
55 Littrup PJ, Aoun HD, Adam B, Krycia M, Prus M, Shields A. Percutaneous cryoablation of hepatic tumors: long-term experience of a large U.S. series. Abdom Radiol (NY) 2016;41(04):767-780

56 Bing F, Garnon J, Tsoumakidou G, Enescu I, Ramamurthy N, Gangi A. Imaging-guided percutaneous cryotherapy of bone and soft-tissue tumors: what is the impact on the muscles around the ablation site? AJR Am J Roentgenol 2014;202(06):1361-1365

57 Garnon J, Cazzato RL, Caudrelier J, et al. Adjunctive thermoprotection during percutaneous thermal ablation procedures: review of current techniques. Cardiovasc Intervent Radiol 2019;42 (03):344-357

58 Auloge P, Cazzato RL, Rousseau C, et al. Complications of percutaneous bone tumor cryoablation: a 10-year experience. Radiology 2019;291(02):521-528

59 Lee TC, Guenette JP, Moses ZB, Chi JH. MRI-guided cryoablation of epidural malignancies in the spinal canal resulting in neural decompression and regrowth of bone. AJR Am J Roentgenol 2019;212(01):205-208

60 Lecigne R, Garnon J, Cazzato RL, et al. Transforaminal insertion of a thermocouple on the posterior vertebral wall combined with hydrodissection during lumbar spinal radiofrequency ablation. AJNR Am J Neuroradiol 2019;40(10):1786-1790

61 Kurup AN, Callstrom MR. Ablation of musculoskeletal metastases: pain palliation, fracture risk reduction, and oligometastatic disease. Tech Vasc Interv Radiol 2013;16(04):253-261

62 Khodarahmi I, Bonham LW, Weiss CR, Fritz J. Needle heating during interventional magnetic resonance imaging at 1.5- and 3.0-T field strengths. Invest Radiol 2020;55(06):396-404

63 Campbell C, Lubner MG, Hinshaw JL, Muñoz del Rio A, Brace CL. Contrast media-doped hydrodissection during thermal ablation: optimizing contrast media concentration for improved visibility on CT images. AJR Am J Roentgenol 2012;199(03): 677-682

64 Lea W, Tutton S. Decision making: osteoplasty, ablation, or combined therapy for spinal metastases. Semin Intervent Radiol 2017;34(02):121-131

65 Cazzato RL, Garnon J, Ramamurthy N, et al. Percutaneous imageguided cryoablation: current applications and results in the oncologic field. Med Oncol 2016;33(12):140

66 Munk PL, Murphy KJ, Gangi A, Liu DM. Fire and ice: percutaneous ablative therapies and cement injection in management of metastatic disease of the spine. Semin Musculoskelet Radiol 2011;15(02):125-134

67 Garnon J, Koch G, Caudrelier J, Tsoumakidou G, Cazzato RL, Gangi A. Expanding the borders: Image-guided procedures for the treatment of musculoskeletal tumors. Diagn Interv Imaging 2017;98(09):635-644

68 Pimolsanti R, Wongkajornsilpa A, Chotiyarnwong P, Asavamongkolku A, Waikakul S. Effects of thermoablation with or without caffeine on giant cell tumour of bone. J Orthop Surg (Hong Kong) 2015;23(01):95-99

69 Rosenthal DI, Alexander A, Rosenberg AE, Springfield D. Ablation of osteoid osteomas with a percutaneously placed electrode: a new procedure. Radiology 1992;183(01):29-33

70 Rosenthal D, Callstrom MR. Critical review and state of the art in interventional oncology: benign and metastatic disease involving bone. Radiology 2012;262(03):765-780

71 Husband DJ. Malignant spinal cord compression: prospective study of delays in referral and treatment. BMJ 1998;317 (7150):18-21

72 Thacker PG, Callstrom MR, Curry TB, et al. Palliation of painful metastatic disease involving bone with imaging-guided treatment: comparison of patients' immediate response to radiofrequency ablation and cryoablation. AJR Am J Roentgenol 2011; 197(02):510-515

73 Cazzato RL, Arrigoni F, Boatta E, et al. Percutaneous management of bone metastases: state of the art, interventional strategies and joint position statement of the Italian College of MSK Radiology 
(ICoMSKR) and the Italian College of Interventional Radiology (ICIR). Radiol Med (Torino) 2019;124(01):34-49

74 Mastier C, Gjorgjievska A, Thivolet A, et al. Musculoskeletal metastases management: the interventional radiologist's toolbox. Semin Intervent Radiol 2018;35(04):281-289

75 Mayer T, Cazzato RL, De Marini P, et al. Spinal metastases treated with bipolar radiofrequency ablation with increased $\left(>70^{\circ} \mathrm{C}\right)$ target temperature: pain management and local tumor control. Diagn Interv Imaging 2020; May 29 (Epub ahead of print)

76 Thompson SM, Callstrom MR, McKusick MA, Woodrum DA. Initial results of image-guided percutaneous ablation as second-line treatment for symptomatic vascular anomalies. Cardiovasc Intervent Radiol 2015;38(05):1171-1178

77 Sag AA, Maybody M, Comstock C, Solomon SB. Percutaneous image-guided ablation of breast tumors: an overview. Semin Intervent Radiol 2014;31(02):193-202

78 Erinjeri JP, Fine GC, Adema GJ, et al. Immunotherapy and the interventional oncologist: challenges and opportunities-a society of interventional oncology white paper. Radiology 2019;292(01):25-34

79 Kim D, Erinjeri JP. Postablation immune microenvironment: synergy between interventional oncology and immuno-oncology. Semin Intervent Radiol 2019;36(04):334-342

80 Meek RD, Mills MK, Hanrahan CJ, et al. Pearls and pitfalls for softtissue and bone biopsies: a cross-institutional review. Radiographics 2020;40(01):266-290

81 Cazzato RL, Auloge P, Dalili D, et al. Percutaneous image-guided cryoablation of osteoblastoma. AJR Am J Roentgenol 2019;213 (05):1157-1162

82 Autrusseau P-A, Cazzato RL, De Marini P, et al. Percutaneous MRguided cryoablation of low-flow vascular malformation: technical feasibility, safety and clinical efficacy. Cardiovasc Intervent Radiol 2020;43(06):858-865

83 Fritz J, Sonnow L, Morris CD. Adjuvant MRI-guided percutaneous cryoablation treatment for aneurysmal bone cyst. Skeletal Radiol 2019;48(07):1149-1153

84 Thibaut A, Bouhamama A, Boespflug A, et al. Percutaneous cryotherapy for treatment of chondroblastoma: early experience. Cardiovasc Intervent Radiol 2019;42(02):304-307

85 Cazzato RL, Garnon J, Shaygi B, et al. How to perform a routine cryoablation under MRI guidance. Top Magn Reson Imaging 2018;27(01):33-38

86 Cazzato RL, De Marini P, Leclerc L, et al. Large nearly spherical ablation zones are achieved with simultaneous multi-antenna microwave ablation applied to treat liver tumours. Eur Radiol 2020;30(02):971-975

87 Deib G, Deldar B, Hui F, Barr JS, Khan MA. Percutaneous microwave ablation and cementoplasty: clinical utility in the treatment of painful extraspinal osseous metastatic disease and myeloma. AJR Am J Roentgenol 2019;212(06):1-8
88 Khan MA, Deib G, Deldar B, Patel AM, Barr JS. Efficacy and safety of percutaneous microwave ablation and cementoplasty in the treatment of painful spinal metastases and myeloma. AJNR Am J Neuroradiol 2018;39(07):1376-1383

89 Sequeiros RB, Fritz J, Ojala R, Carrino JA. Percutaneous magnetic resonance imaging-guided bone tumor management and magnetic resonance imaging-guided bone therapy. Top Magn Reson Imaging 2011;22(04):171-177

90 Napoli A, Mastantuono M, Cavallo Marincola B, et al. Osteoid osteoma: MR-guided focused ultrasound for entirely noninvasive treatment. Radiology 2013;267(02):514-521

91 Bazzocchi A, Napoli A, Sacconi B, et al. MRI-guided focused ultrasound surgery in musculoskeletal diseases: the hot topics. Br J Radiol 2016;89(1057):20150358

92 Bing F, Vappou J, de Mathelin M, Gangi A. Targetability of osteoid osteomas and bone metastases by MR-guided high intensity focused ultrasound (MRgHIFU). Int J Hyperthermia 2018;35(01): 471-479

93 Huisman M, ter Haar G, Napoli A, et al. International consensus on use of focused ultrasound for painful bone metastases: current status and future directions. Int J Hyperthermia 2015; 31(03):251-259

94 Napoli A, Anzidei M, Marincola BC, et al. MR imaging-guided focused ultrasound for treatment of bone metastasis. Radiographics 2013;33(06):1555-1568

95 Napoli A, Bazzocchi A, Scipione R, et al. Noninvasive therapy for osteoid osteoma: a prospective developmental study with MR imaging-guided high-intensity focused ultrasound. Radiology 2017;285(01):186-196

96 Ghanouni P, Dobrotwir A, Bazzocchi A, et al. Magnetic resonanceguided focused ultrasound treatment of extra-abdominal desmoid tumors: a retrospective multicenter study. Eur Radiol 2017;27(02):732-740

97 Scipione R, Anzidei M, Bazzocchi A, Gagliardo C, Catalano C, Napoli A. HIFU for bone metastases and other musculoskeletal applications. Semin Intervent Radiol 2018;35(04):261-267

98 Deipolyi AR, Golberg A, Yarmush ML, Arellano RS, Oklu R. Irreversible electroporation: evolution of a laboratory technique in interventional oncology. Diagn Interv Radiol 2014;20(02):147-154

99 Krum H, Schlaich M, Whitbourn R, et al. Catheter-based renal sympathetic denervation for resistant hypertension: a multicentre safety and proof-of-principle cohort study. Lancet 2009; 373(9671):1275-1281

100 Arena CB, Sano MB, Rossmeisl JH Jr, et al. High-frequency irreversible electroporation (H-FIRE) for non-thermal ablation without muscle contraction. Biomed Eng Online 2011;10:102

101 Cazzato RL, Garnon J, Koch G, et al. Musculoskeletal interventional oncology: current and future practices. Br J Radiol 2020; August 12 (Epub ahead of print) 